\title{
Computer Modeling in the Application to Geothermal Engineering
}

\author{
Karpenko Vasily Nikolaevich $\left(\mathbb{D},{ }^{1}\right.$ Yuriy Starodub $\mathbb{D},^{2}$ and Andrii Havrys $\mathbb{D}^{2}$ \\ ${ }^{1}$ National Joint-Stock Company "Naftogaz of Ukraine", 6, Bohdan Chmelnycky Street, Kyiv 01601, Ukraine \\ ${ }^{2}$ Lviv State University of Life Safety, 35 Kleparivska Street, Lviv 79007, Ukraine
}

Correspondence should be addressed to Yuriy Starodub; george_starodub@yahoo.com

Received 5 October 2020; Revised 23 June 2021; Accepted 17 July 2021; Published 10 August 2021

Academic Editor: Hui Yao

Copyright (c) 2021 Karpenko Vasily Nikolaevich et al. This is an open access article distributed under the Creative Commons Attribution License, which permits unrestricted use, distribution, and reproduction in any medium, provided the original work is properly cited.

In the article, investigation is given of the developed mathematical models of nonequilibrium in time and distributed in space thermodynamic state of Earth's matter from its center to its surface depending on the cases of the presence and absence of an internal source of thermal energy concentrated in the center of mass taking into account known geophysical data about the nucleus, mantle, lithosphere and atmosphere, and endogenous and exogenous heat fluxes. The objects of research are as follows: mathematical models of geothermal energy of the Earth, its internal source, and heat balance of endogenous and exogenous heat fluxes on the Earth's surface. Research methods used are as follows: thermometry in deep wells, ground and remote sensing of heat fluxes of the Earth and the planets of the Solar System, mathematical modeling of heat exchange and thermoelastic processes from compression of Earth's matter by gravitational field energy information and classical physical and mathematical methods, and computer modeling. The aim of research: in computer modeling to provide new mathematical models that determine the geophysical parameters of geothermal energy, which are aimed on solving problems of energy, environmental and economic security of society, using modern technical means of calculating ground and remote sensing data development of geothermal resources, and regulation of the heat balance of the ecosystem, namely: (i) study of the geological structure of the lithosphere to a depth of $10 \mathrm{~km}$ by remote sensing to determine the physical parameters of its layers more accurately than ground methods; (ii) development of projects of geothermal power plants on the basis of single isolated wells of a given depth with a capacity of up to $2 \div 3 \mathrm{~mW}$ of electricity on continents of the globe; (iii) real-time monitoring and forecasting of the temperature field of the atmosphere according to its physical and chemical composition. The novelty of the obtained research results: (i) developed the mathematical model of the physical process of origin and distribution in the bowels of the density of geothermal energy of the Earth from the surface to its center, which is the density of internal energy of an elementary geological object, and which increases when approaching the center of the planet; (ii) developed the mathematical model of the thermal energy source of infrared (IR) waves of the elementary geophysical object of the Earth's interior depending on the depth of its occurrence, which allows to determine the stable generation of geothermal energy by rocks in a deep well for extraction and conversion into electricity and to study the geological structure and physical properties of the Earth's interior; (iii) the mathematical model of heat exchange between the layers of the Earth's subsoil with the thermal energy of infrared waves according to the laws of Fourier thermal conductivity and Stefan-Boltzmann heat transfer, which together with the geothermal energy source model allows to determine a thermal capacity of rocks in a deep well; (iv) developed the mathematical model of stable action of a source of thermal energy in the center of mass of the Earth, in the absence of which it is hard to explain the power of its endogenous infrared heat flux, parameters of geothermal energy distribution in the Earth, and the current thermodynamic state of the atmosphere, and the change in temperature of which depends on the thermophysical parameters of the physical-chemical composition of the atmosphere more than on changes in the thermal activity of the Sun; (v) determination of new numerical values: thermophysical parameters of the Earth's interior; kinetic, potential and own gravitational energy of the Earth and own gravitational energy of the planets of the Solar System. 


\section{Introduction}

The process of development of geothermal resources (GTRs) for energy, environmental and social security of local society is growing in many countries around the world. The experience (of the Organic Rankine Cycle World) of using GTR shows that the most promising technology for the use and conversion of geothermal energy into thermal and electrical energy consumption is electric geothermal station technology based on an isolated single well (EGS-ISW). However, the current scientific and technical level of means of development of GTR does not allow to make this technology economically attractive. The reason is the lack of an adequate unified physical idea of the nature of geothermal energy. Existing physical ideas about the origin of geothermal energy are based on two hypotheses: "cold" and "hot" Earth [1], which do not answer a number of important questions for the development of society based on geothermal energy, which arise in the analysis of endogenous and exogenous thermal flows of the Earth.

At the same time, the experience [1] of drilling deep, more than $3500 \mathrm{~m}$, oil and gas wells and special experimental studies [2] of wells with a depth of more than $4000 \mathrm{~m}$ show that single deep wells have significant potential for stable heat generation up to $15 \mathrm{MW}$, which increases with the depth of the well. This GTR can be widely used.

In [3], an analysis of 94 electric geothermal stations (EGSs) located around the world was performed. The analysis showed that the scientific and technical level created by EGS for the use of geothermal waters and the conversion of their thermal energy into electricity provides different efficiencies of $1 \div 27 \%$ of their work. The economic efficiency of EGS is less than 5 years and depends on the generation of absolute power of thermal energy for consumption. The efficiency of EGS-ISW technology $[4,5]$ has a similar technical efficiency of converting thermal energy into electricity, but the economic efficiency has a payback period of more than 5 years.

The task of the article is to provide and prove a physical representation of the hypothesis of "hot" Earth about the nature of geothermal energy, the conversion of gravitational energy into thermal energy, and to investigate the developed complex mathematical substantiation of this representation on known ground and remote sensing data tasks of development of geothermal resources, ecological monitoring, and forecasting of thermodynamic state of the atmosphere.

For heat and mass transfer problems, in particular, for EGS-ISW technology, studies of the thermal conductivity of nanofluids play an important role [6]. In addition to thermal conductivity, nanofluids have lubricating, anticorrosive, absorbing properties of thermal energy of IR waves. The results obtained in this work on the complexation of conductive and radiative thermal conductivity allow us to study the energy-absorbing properties of infrared waves by nanofluids of different composition.

\section{Materials and Methods}

We study the geothermal model of the Earth with radiate and conductive endogenous and exogenous heat fluxes, taking into account well-known geophysical parameters, namely: the distribution of average temperatures in its subsoil and on the surface and its external general gravitational, internal potential, and kinetic energy using an energy method. The statement involves an interpretation of the joint action in every point of the physical space of the conservation, change, and transfer energy laws [7].

Consider the known energy balance of radiated exogenous and endogenous heat fluxes on the Earth's surface.

The proposed geothermal model of the Earth (GTME) with thermal flows has the form

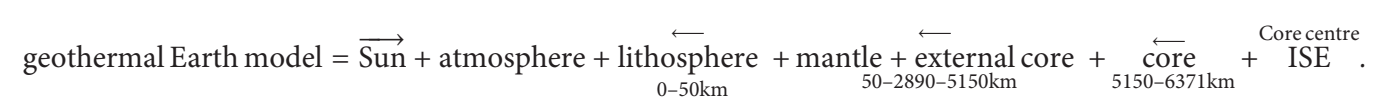

Thus, the geothermal model of the Earth includes energies of the Sun + atmosphere + lithosphere + (Earth mantle + outer core) + core + internal source of the Earth (ISE) based on the laws of thermodynamics, in which the ISE has a constant power of $1.859 \cdot 10^{17} \mathrm{~W}\left(364.46 \mathrm{~W} / \mathrm{m}^{2}\right)$, which is observed at a depth of $50 \mathrm{~m}$. The model works as follows: ISE heats the inner core, which cools, heating the outer core and mantle. Cooling of the mantle is accompanied by the heating of the lithosphere. And the cooling of the lithosphere takes place also due to the influence of the atmosphere, which cools with the density of the radiation flux of $239.9 \mathrm{~W} / \mathrm{m}^{2}$ of infrared waves. The analysis of the thermal balance of the Earth shows that the atmosphere passes $66 \%$ of the IR waves. The heat flux of short IR waves penetrates on the Earth's surface from the Sun and is absorbed at the level $0.41 \cdot 10^{17} \mathrm{~W}$ $\left(161 \mathrm{~W} / \mathrm{m}^{2}\right)$ [8] and $\left(163.3 \mathrm{~W} / \mathrm{m}^{2}\right)[9,10]$.

According to the authors of this article, the density of the thermal flux of $398.2 \mathrm{~W} / \mathrm{m}^{2}$ from the medium and long infrared waves corresponds to an average temperature of the Earth's surface, which is $16.3^{\circ} \mathrm{C}$ according to the Stefan-Boltzmann law. At a depth of $50 \mathrm{~m}$, where the typical temperature is $10^{\circ} \mathrm{C}$, exogenous and endogenous heat fluxes are formed with opposite gradients. Therefore, the conductive cooling of the Earth at this depth is almost stopped. The Earth is in an adiabatic thermodynamic state. The temperature of the lithosphere at a depth of $50 \mathrm{~m}$ remains unchanged at an average temperature of $10^{\circ} \mathrm{C}(283.15 \mathrm{~K})$ with a corresponding heat flux density of $364.46 \mathrm{~W} / \mathrm{m}^{2}$. 
A similar adiabatic situation is experimentally established on the Mercury and the Moon [11].

The research of GTME is carried out by the method of energy analysis (MEA) [12] using the laws of thermodynamics and the function of deterministic probability (FDP) [6]. The main ideas of the MEA are the idea of a coherent action at each point of the physical space of laws: conservation, modification, transport, and packing of energy in physical points.

The adiabatic distribution of temperatures in the middle of the planets is considered in the work [13].

The average conductive heat flux for the Earth model assumed spherical is of $\eta_{3}=\eta \cdot 4 \pi R_{3}^{2}=4.42 \cdot 10^{13} \mathrm{~W}$ $\left(\eta=0.087 \mathrm{~W} / \mathrm{m}^{2}\right)$, where $R_{3}$ is the average radius of the Earth. The heat flux existence on the Earth's surface (at an average depth of $50 \mathrm{~m}$ ) and a stable generation of significant thermal energy continued by deep wells requires a much greater density of thermal energy. Thus, the heat flux cannot be considered the main thermal flux of cooling the Earth and heating the energy in the well. Then, the question about the physical cause of the origin of an endogenous heat flux in the geological environment (GE) arises.

The authors of this article explain the physical fact of the thermogradient in the GE with difference between the stationary thermoplastic states of the rocks at the depth of their occurrence, the main factor. In addition, we consider additional anomalies: different horizontal tectonic stresses and faults, different fluid saturation, physic-chemical transformations, different composition of rocks absorbing the particle, the main heat flux of the IR wave of the ISE, and the proximity of the magmatic activity. The accumulated gravitational energy in the unit volume of rocks in depth increases their internal energy, which leads to an increase in their temperature and volume modulus of elasticity. That is, the internal energy of rocks at each depth is in thermodynamic equilibrium with gravitational energy. The Stefan-Boltzmann law determines temperature of rocks at each point in the vertical direction. The temperature of rocks supposedly forms the heat exchange determined by the Fourier thermal conductivity law. In fact, there is no such heat exchange, but there is a fixation of various stationary thermodynamic states of rocks. This fact proves the method of thermometry in deep wells, when the washer fluid, after a day's carrying, on the face is $130^{\circ} \mathrm{C}$ and at the mouth is $10^{\circ} \mathrm{C}$.

For example, for rocks with a blackness factor $\varepsilon=0.68$, temperature $T_{3}=283.15 \mathrm{~K}$ at a depth of $50 \mathrm{~m}$, coefficient of thermal conductivity $\lambda_{f}=3.5 \mathrm{~W} / \mathrm{m} / \mathrm{K}, \operatorname{grad}\left(T_{3}\right)=0.03 \mathrm{~K} /$ $\mathrm{m}$, coefficient of radiation absorption $\alpha_{R}=-(\mathrm{d} \eta / \eta \mathrm{d} z)$ $=1 \mathrm{~m}^{-1}$ for large thicknesses, and normalized on $z_{0}=1 \mathrm{~m}$, when the absorption is equal to radiation, the equation holds

$$
\begin{aligned}
& \eta=\lambda_{f} \cdot \operatorname{grad}\left(T_{3}\right)=z_{0} \cdot \alpha_{R} \varepsilon \sigma\left[\left\{T_{3}+z_{0} \cdot \operatorname{grad}\left(T_{3}\right)\right\}^{4}-T_{3}^{4}\right] \\
& \eta=3.5 \cdot 0.03 \approx 1 \cdot 1 \cdot 0.68 \cdot 5.67 \cdot 10^{-8} \cdot\left\{[10+273.15+1 \cdot 0.03]^{4}-[10+273.15]^{4}\right\}=0.105\left(\mathrm{~W} / \mathrm{m}^{2}\right)
\end{aligned}
$$

Formula (2) reflects the equality of the heat flux density according to the law of Fourier thermal conductivity in the left part and the Stefan-Boltzmann law in the right-hand side. In the right-hand side here, the difference between the density of the heat flux emitted in the linear approximation, which increases with depth, and the density of the heat flux that occurs for the temperature of the Earth $T_{3}$ is recorded. That is, a differential equation for the distribution of temperature at depth for a stationary thermodynamic state of the form is fair in GE:

$$
\lambda_{f} \cdot \operatorname{grad}\left(T_{3}\right)=z_{0} \cdot \alpha_{R} \varepsilon \sigma\left[\left\{T_{3}+z_{0} \cdot \operatorname{grad}\left(T_{3}\right)\right\}^{4}-T_{3}^{4}\right],
$$

or

$$
\widetilde{T}^{4}(z)-a \widetilde{T}(z)+b=0 .
$$

Here, $a=\left(\lambda_{f} /\left(z_{0}^{2} \cdot \alpha_{R} \varepsilon \sigma\right)\right), b=\left(a \cdot T_{3}-T_{3}^{4}\right)$ are coefficients of layers of the GE at a given depth, which vary with depth and composition of rocks, and $\widetilde{T}(z)=\left[z_{0}\left(\mathrm{~d} T_{3}(z) /\right.\right.$ $\left.\mathrm{d} z)+T_{3}(z)\right]$ is the temperature of the GTME, K. The temperature depends on two main factors, namely, on the comprehensive compression and absorption of a portion of the energy of electromagnetic waves emitting by internal Earth's source (ISE) from the depths under the law of
Stefan-Boltzmann at the surface temperature of the nucleus $6273 \mathrm{~K}, \sigma=5.67 \cdot 10^{-8} \mathrm{~W} / \mathrm{m}^{2} / \mathrm{K}^{4}$, Stefan-Boltzmann constant.

The energy of the waves of the ISE has the density $364.46 \mathrm{~W} / \mathrm{m}^{2}$ on the surface of the lithosphere, which forms the stationary temperature according to Stefan-Boltzmann's law $T_{30}=(10+273.15) \mathrm{K}$. As the depth increases, the temperature of the rocks increases; that is, the Earth's temperature $T_{3}$ is a function of the density of gravitational energy $T_{3}\left(E_{G}\right)$, where $E_{G}$ is the gravitational energy of the Earth, which increases to the center to the final value.

The temperature of the GTME depends on the gravitational energy. Experimental and theoretical geophysical studies of temperature dependence and the stress state of rocks on the depth of their occurrence, performed by the authors of this article, allowed to develop a function $T_{3}\left(E_{G}\right)$.

The authors of this paper use the theory of Debye's solids $[14,15]$, which determines the volume density of the thermal energy $e(T)$ of a solid, and the energy approach to modeling the change of the volume elastic modulus in the GTME from the change in gravitational energy $e\left(E_{G}\right)$. The authors propose and investigate the relationship between the density of elastic energy, which depends on its own gravitational energy, and the density of thermal energy in the Earth's lithosphere by the equation 


$$
e(T)=e\left(E_{G}\right) \longrightarrow \rho \frac{3 \pi^{4}}{5 \mu} \cdot \frac{R \cdot T_{3}^{4}\left(E_{G}\right)}{T_{D}^{3}\left(E_{G}\right)}=\rho V_{p}^{2}\left(E_{G}\right)\left(\mathrm{J} / \mathrm{m}^{3}\right) .
$$

From (6) for a temperature dependent on gravitational energy, we have

$$
T_{3}\left(E_{G}\right)=\sqrt[4]{\frac{5 \mu_{3}}{3 R \pi}\left(\frac{\hbar}{k_{B}} \frac{2}{\lambda_{\min }}\right)^{3} V_{p}^{5}\left(E_{G}\right)}(\mathrm{K}),
$$

where $R=8.31451 \mathrm{~J} / \mathrm{moles} / \mathrm{K}$ which is the universal gas constant; $\hbar=6.626 \cdot 10^{-34} \mathrm{~J}$.s which is Planck's constant; $k_{B}=1.380648 \cdot 10^{-23} \mathrm{~J} / \mathrm{K}$ which is the Boltzman constant; $\mu_{3}, \rho$ are the molar mass and density of matter of the planet, respectively, $\mathrm{kg} / \mathrm{mol}, \mathrm{kg} / \mathrm{m}^{3} ; T\left(E_{G}\right), T_{D}=\left(\hbar \Omega_{\max } / k\right)$ are the inner temperature and temperature Debye matter of the planet, $\mathrm{K} ; \Omega_{\max }=2 \pi\left(V_{p}\left(E_{G}\right) / \lambda_{\min }\right)$ which is the planet's matter maximum frequency of oscillations of elementary objects, depending on its gravitational energy, $\mathrm{s}^{-1} ; V_{P}\left(E_{G}\right)=$ $V_{P 0} \sqrt{\left[1+\ln \left\{1+\left(E_{G}(z) / w_{0} e_{g}(z)\right)\right\}\right.}$ which is the $P$-wave propagation velocity at depth $z$ in the GE, $\mathrm{m} / \mathrm{s}[16] ; V_{P 0}$ is the average velocity of the $P$-wave on the surface of the planet, $\mathrm{m} / \mathrm{s} ; e_{g}(z)=\rho(z) V_{P}^{2}(z)$ which is the volumetric density of elastic energy, $\mathrm{J} / \mathrm{m}^{3} ; w_{0}=1$ which is the unit volume of $\mathrm{GE}$, $\mathrm{m}^{3} ; \lambda_{\min }=\left(\hbar / k_{B}\right) \cdot\left(\left(V_{s-\text { in }} \cdot V_{p-\text { in }}\right) / T_{D_{-} \mathrm{Fe}}\right) \cdot \sqrt[3]{12 \pi^{2} /\left(V_{s-\text { in }}^{3}\right.}$ $\left.+V_{p-\text { in }}^{3}\right)=7.368 \cdot 10^{-10} \mathrm{~m}$ which is the actual minimum length of the acoustic wave in the core of the Earth, $\mathrm{m} ; V_{s \text {-in }}=$ $3474, V_{p-\text { in }}=11260$ which is the interval speeds of $S$ - and $P$ waves, respectively, $\mathrm{m} / \mathrm{s} ; T_{D_{-} \mathrm{Fe}}=1096.68 \mathrm{~K}$ which is the temperature of Debye for iron in the core (Table 1); and $E_{G}(z)=-\gamma \int_{R}^{R-z_{m}}(m(z) /(R-z)) \mathrm{d} m(z)$ which is the gravitational energy of the planet, J.

The Earth's own total gravitational energy, provided by $\rho=\rho_{0}+\chi \cdot z$, is determined by the integral

$$
\begin{aligned}
E_{G}(z) & =-\gamma \int_{R_{3}}^{R_{3}-z_{m}} \frac{m(z)}{R_{3}-z} \mathrm{~d} m(z)=\left\{m(z)=\frac{4 \pi}{3}\left(\rho_{0}+z \chi\right) z^{3} ; \mathrm{d} m(z)=\left(3 \rho_{0}+4 z \chi\right) \frac{4 \pi}{3} z^{2} \mathrm{~d} z\right\}= \\
& =-\gamma\left\{\int_{R_{3}}^{R_{3}-z_{m}} \frac{3 \rho_{0}^{2} z^{5}}{R_{3}-z} \mathrm{~d} z+\int_{R_{3}}^{R_{3}-z_{m}} \frac{7 \chi \rho_{0} z^{6}}{R_{3}-z} \mathrm{~d} z+\int_{R_{3}}^{R_{3}-z_{m}} \frac{4 \chi^{2} z^{7}}{R_{3}-z} \mathrm{~d} z\right\} \\
& =-3 \gamma \rho_{0}^{2}\left(\frac{4 \pi}{3}\right)^{2}\left[\frac{137}{60}+\ln |\sigma|\right] R_{3}^{5}--7 \gamma \chi \rho_{0}\left(\frac{4 \pi}{3}\right)^{2}\left[\frac{882}{360}+\ln |\sigma|\right] R_{3}^{6}-4 \gamma \chi^{2}\left(\frac{4 \pi}{3}\right)^{2}\left[\frac{6534}{2520}+\ln |\sigma|\right] R_{3}^{7},
\end{aligned}
$$

where $|\sigma|=\left(\left(R_{3}-z_{m}\right) / R_{3}\right), z_{m}=6301000 \mathrm{~m}$, which is the depth of integration, $R_{3}=6371008.8 \mathrm{~m}$ which is the radius of the Earth, and $\left(\left(\rho_{m}-\rho_{0}\right) / R_{3}\right)=\chi$ which is the increasing density to the center of the Earth; $\rho_{m}=13290 \mathrm{~kg} / \mathrm{m}^{3}$, and $\rho_{0}=2850 \mathrm{~kg} / \mathrm{m}^{3}$, being equal to $2.6275 \cdot 10^{33} \mathrm{~J}$. The known [19-21] gravitational energy of the Earth is defined at the level of $\quad E_{G}(z)=\gamma \quad \int_{0}^{R}\left(m_{3}(z) / z\right) \mathrm{d} m_{3}(z)=(3 / 5) \gamma\left(m_{3}^{2}\right.$ $(z) / z)=2.23945 \bullet 10^{32} \mathrm{~J}, m_{3}(z)=\rho_{3} W_{3}(z), \rho_{3}=$ const.

Figure 1 shows the characteristics of the Earth's own gravitational energy determined according to Table 1 equations of the form

$$
\begin{aligned}
\underbrace{\left[e^{\left(\left(V_{P-\text { teor }}^{2}(z) / V_{0}^{2}\right)-1\right)}-1\right] \rho_{\text {fact }}(z) V_{P-\text { fact }}^{2}(z) \cdot w_{0}}_{E_{G}(z) \text {-teor EIM }} & =E_{G}(z)=\underbrace{\gamma \int_{R-z_{m}}^{R} \frac{m(z)}{R-z} \mathrm{~d} m(z) ;}_{E_{G}(z) \text {-teor Newton's method }} e_{\text {teor }}(z)=\left(\rho_{0}+\chi z\right) V_{P \text {-teor }}^{2}, \\
V_{P-\text { teor }}^{2} & =V_{0}^{2}\left[1+\ln \left(1+\frac{E_{G}(z)}{\rho_{\text {fact }}(z) V_{P-\text { fact }}^{2}(z) \cdot w_{0}}\right)\right] ; \\
e_{\text {fact }}(z) & =\rho_{\text {fact }}(z) V_{P-\text { fact }}^{2}(z) ; \\
e_{\text {teor }+ \text { fact }}(z) & =\rho_{\text {fact }}(z) V_{P-\text { teor }}^{2}(z) .
\end{aligned}
$$


TABLe 1: Physical parameters of the crust of the geological medium (GM) according to the main physical-chemical elements [17]

\begin{tabular}{|c|c|c|c|c|c|}
\hline Parameters of physical-chemical elements & $\mathrm{Si}$ & $\mathrm{O}$ & $\mathrm{Al}$ & GM & $\mathrm{Fe}$ \\
\hline Heat capacity $\left(\mathrm{J} / \mathrm{kg} /{ }^{\circ} \mathrm{C}\right)$ & 760 & 919.32 & 902.47 & 816.61 & \\
\hline Heat capacity $(\mathrm{J} / \mathrm{mol} / \mathrm{K})$ & 20.16 & 29.4 & 24.35 & 24.55 & \\
\hline Molar mass $(\mathrm{g} / \mathrm{mol})$ & 28.08 & 15.99 & 26.98 & 19.42 & 55.845 \\
\hline Debye temperature* $(\mathrm{K})$ & 625 & 155 & 394 & 364.44 & $478.46 / 1096.68$ \\
\hline Number of moles per $1 \mathrm{~kg}$ & 35.61 & 62.54 & 37.06 & 51.5 & \\
\hline The composition of the elements in the GM (\%) & 29 & 57 & 8 & 94 & \\
\hline
\end{tabular}

${ }^{*}$ Debye iron temperature is given for normal and core conditions [18].

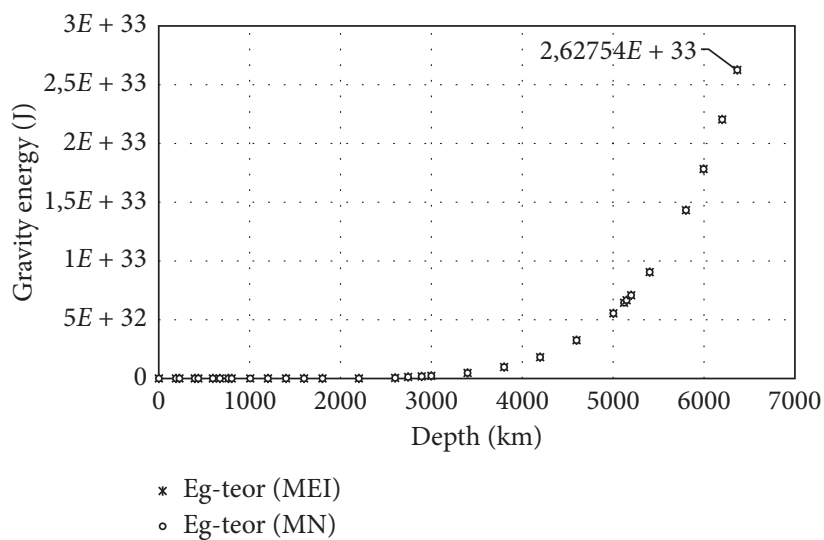

Figure 1: Characteristics of the Earth's own gravitational energy depending on the depth $R_{3}$ from the surface, determined by the energy information method (EIM) and Newton's method (NM).

Figure 2 shows the characteristics of the distribution of the determined energy density of gravitational energy (Table 2) in $1 \mathrm{~m}^{3}$ and the known temperature [22].

The Earth's temperature at a depth $z=50 \mathrm{~m}$ is

$$
T_{3}(z)=\sqrt[4]{\frac{5 \mu_{3}(z)}{3 \pi R}\left(\frac{2 \hbar}{k_{B} \lambda_{3 \min }(z)}\right)^{3} V_{p 03}^{5}(z)}=285.3 \mathrm{~K}
$$

where $\mu_{3}=0.001942 \mathrm{~kg} / \mathrm{mol}$ which is the average molar mass of the Earth's substance (Table 1);

$\lambda_{3 \text { min }}=2 \pi \hbar\left(V_{p 03} / T_{D_{-} \mathrm{GR}} k_{B}\right)=1.5254 \cdot 10^{-9} \mathrm{~m}$ which is the minimum $P$-wavelength, $T_{D_{-} \mathrm{GR}}=364.44 \mathrm{~K}$ which is the average Debye temperature of the geological environment (Table 1); and $V_{p 03}=1850 \mathrm{~m} / \mathrm{s}$ which is the average speed of the $P$-wave at a depth of $50 \mathrm{~m}$.

The temperature of the Earth's core, $z=6371 \mathrm{~km}$, is

$$
T_{3}(z)=\sqrt[4]{\frac{5 \mu_{3}(z)}{3 \pi R}\left(\frac{2 \hbar}{k_{\mathrm{B}} \lambda_{\min }(z)}\right)^{3} V_{P}^{5}(z)}=6128.7 \mathrm{~K}
$$

$$
\text { In addition, } \quad T_{D_{-} \mathrm{Fe}}=T_{0 D_{-} \mathrm{Fe}} \exp ((\kappa / q)
$$
$\left.\left[\rho_{0 \mathrm{Fe}} / \rho_{\max }\right]^{q}\right)=478.46 \cdot \exp (1.4 \cdot(7.868 / 13.29))=1096.68-$ $\mathrm{K}$ which is Debye temperature of iron in the core (Table 1); $\kappa=1.4$ which is the first parameter of Gruneisen; $q=1$ which is the second parameter of Gruneisen; $\lambda_{3 \min }=7.368 \cdot 10^{-10} \mathrm{~m}$ is the minimum $P$-wavelength in the nucleus; $\rho_{0 \mathrm{Fe}}=7.868$ which is the density of iron $[18], \mathrm{g} / \mathrm{m}^{3}$; and $V_{p}(z=6371 \mathrm{~km})=11260 \mathrm{~m} / \mathrm{s}$ which is the average velocity of the $P$-wave in the nucleus [24].

Figure 3 shows the actual characteristics in the GE: (a) distribution of temperature and velocity of the $P$-wave; (b) the distribution of the density of elastic energy $\left[\rho\left(z_{i}\right) \cdot V_{p}^{2}\left(z_{i}\right)\right]$, dotted lines, defined by seismic data.

Figure 4 shows the characteristics of the temperature distribution in the Earth's interior, determined by the theory of elasticity, 1 (Table 2), and the method of the energy analysis, 2 by equation (7), where $\lambda_{\min }(z)=\left(\hbar V_{s-\text { in }} V_{p}\right.$ $\left.-\mathrm{in} / T_{D} k_{B}\right) \quad \sqrt[3]{12 \pi^{2} /\left(V_{s-\text { in }}^{3}+V_{p-\text { in }}^{3}\right)}=2 \pi \hbar\left(V_{P}(z) / T_{D} k_{B}\right) c$, $\left\{V_{s-\text { in }} \sqrt{3}=V_{p-\text { in }} ; c=0.5 \cdot \sqrt[3]{12 / \pi\left(1+\sqrt{3}^{3}\right)}\right\}_{\text {for a homogeneous isotropic medium }}$ $T_{D}(z)=T_{D_{0}} \quad \exp \left((\kappa / q)\left[\rho_{3}(z) / \rho_{\max }\right]^{q}\right), k=1.52, \quad q=1$, $T_{D_{0}}=364.44 \mathrm{~K} ; \quad V_{P}(z)=V_{P}\left(G_{3}\right)$ according to (9); $\mu(z)=\mu_{0}\left(\rho_{3}(z) / \rho_{30}\right), \mu_{0}=0.01942 \mathrm{~g} / \mathrm{mol}, \rho_{30}=2.85 \mathrm{~g} / \mathrm{m}^{3}$, $\rho_{3}(z)$, Table 2 .

In Table 2 for the calculation of gravitational energy at $z=0 \mathrm{~m}$, the velocity of the $P$-wave $V_{p}=1600 \mathrm{~m} / \mathrm{s}$ is taken for water. To calculate the parameters $\lambda_{\min }(z=0), T_{D}(z=0)$, and $T_{Z}(z=0)$, the $P$-wave velocity $V_{p}(z=0)=1850 \mathrm{~m} / \mathrm{s}$ is taken for the crust on the Earth's surface. For $z>0$, the given physical parameters of the Earth are used.

2.1. Notes. (1) Important value in these studies is $\rho_{m} V_{m P}^{2} W_{3}=1.8252 \cdot 10^{33} \mathrm{~J}$ which is the elastic energy in the center of the Earth, where $W_{3}=(4 / 3) \pi R_{3}^{3}$ $=1.08691 \cdot 10^{21} \mathrm{~m}^{3}$ which is the volume of the Earth; $\rho_{m}=13290 \mathrm{~kg} / \mathrm{m}^{3}$ which is the density in the center of the Earth; $V_{m P}=11260 \mathrm{~m} / \mathrm{s}$ which is the velocity of the $P$-wave 


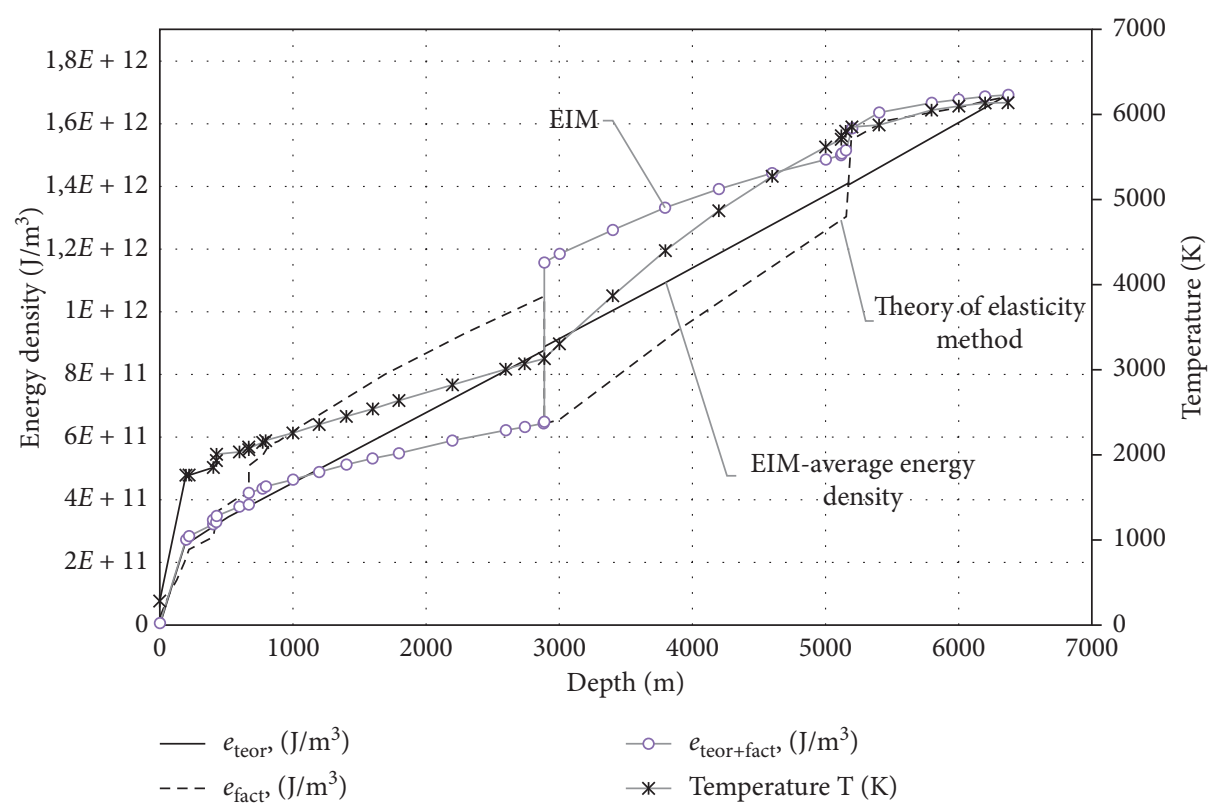

Figure 2: Characteristics of the distribution: gravitational energy densities in the middle of the Earth, determined by the method of the theory of elasticity and EIM and temperature [22].

in the center of the Earth; and $R_{3}$ is the average radius of the Earth, m.

The temperature in the Earth is a consequence of its compression by a gravitational field, which proves the characteristics in Figures 1-4. If in (7), we substitute the value $V_{P}\left(E_{G}\right)$ with the substitution in (9) of the form $\left(E_{G}(z) /\left(\rho_{\text {fact }}(z) V_{P \text {-fact }}^{2}(z) \cdot w_{0}\right)\right)=\left(W / w_{0}\right)$, we obtain qualitative logarithmic characteristics of the maximum temperature in the center of the nuclei depending on the gravitational energy $U$ (volume $W$ ) of the planet (Figure 5).

$$
\begin{gathered}
\ln (\mathrm{T}) \equiv f(U)=\varepsilon \cdot \ln [\sqrt{1+\ln (1+U)} \cdot \sqrt[4]{\sqrt{1+\ln }} \\
(1+U)] \simeq \varepsilon \cdot \ln [\sqrt{1+\ln (1+W)} \cdot \sqrt[4]{\sqrt{1+\ln (1+W)}}], \quad \text { on }
\end{gathered}
$$
the $y$-axis, as an analogue of equation (7), where $U=6 \cdot \widetilde{E}_{G}(z) \approx E_{G}(z)$, the planet's own gravitational energy (Table 3 ), where the column numbers indicate the following: 1 is the name of the planet, 2 is the mass of the planet, 3 is the gravitational energy of the planet, 4 is the solar constant of the planet, 5 is the logarithm of the planet's mass, 6 is the albedo of the planet, 7 is the total power of endogenous heat flow of the planet, 8 is the night total heat flow on the planet's surface, 9 is the day total heat flow on the planet's surface, 10 is the distance of the planet from the Sun, 11 is the absolute average daytime temperature of the planet's surface, 12 is the absolute average nighttime temperature of the planet's surface, 13 is the absolute temperature of the planet's core), $\mathrm{J} ; M$ is the mass of planets, $\mathrm{kg} ; \mathrm{R}$ is the radius of the planet, $\mathrm{m} ; \varepsilon=3.21$ is the coefficient of scale of normalization of the characteristic; temperatures of the nuclei of the planets $f\left(T_{\max }\right)=\ln \left(T_{\max }\right)$, where $T_{\max }$ is the known temperatures of the nuclei of the planets [26], $K$, and masses of planets $\ln (M)$, on the abscissa.

In Figure 5, the characteristics of the planet's core temperature functions indicate a qualitative physical relationship between the maximum temperature in the center of the core and the planet's gravitational energy. The analysis of the characteristic $f(U)$ points to the hypothesis, a constant temperature in the center of the nuclei of the planets. Provided $E_{G}(z)=\rho_{\text {fact }}(z) V_{P \text {-fact }}^{2}(z) W$, the characteristic $f(U)=$ const (approximation $f(U), f\left(T_{\max }\right)$ in EXCEL).

2.2. Development of Geothermal Model of the Earth with Heat Fluxes. The task is to investigate the nonstationary thermodynamic state of the Earth depending on the power of the internal source of the Earth and the external heat flux from the Sun according to the known temperature distribution in the Earth's interior $\mathrm{T}_{3}(z)$ from Table 2.

Equation (2) is considered in the form $\sigma\left(\tau(z)+z_{m}(\mathrm{~d} \tau(z) / \mathrm{d} z)\right)^{4}=\lambda_{\mathrm{SB}}(\mathrm{d} \tau(z) / \mathrm{d} z)+\sigma \tau^{4}(z)$, the radiant transfer of thermal energy in a unit volume of the geological environment, in which the term $\tau(z)+z_{m}(\mathrm{~d} \tau(z) / \mathrm{d} z)=\mathrm{T}_{m}$ has heating to a temperature $\mathrm{T}_{m}$ at an unknown coordinate $z_{m}$ at known parameters $z, \tau(z), \mathrm{T}_{m}, T_{0}$, namely,

$$
\begin{aligned}
z_{m} & =-z \cdot\left\{\ln \left|\frac{\mathrm{T}_{m}-\tau(z)}{\mathrm{T}_{m}-\mathrm{T}_{0}}\right|\right\}^{-1} \longrightarrow \tau(z) \\
& =\mathrm{T}_{m}-\left(\mathrm{T}_{m}-\mathrm{T}_{0}\right) \exp \left(-\frac{z}{z_{m}}\right) .
\end{aligned}
$$

ISE is a source of electromagnetic waves, and an energy of which is partially absorbed by matter of the Earth and partly radiated into the open physical space. Simulating the data of physical processes for the Earth, using the results of work [20], we perform a system of equations of the formecmath; 


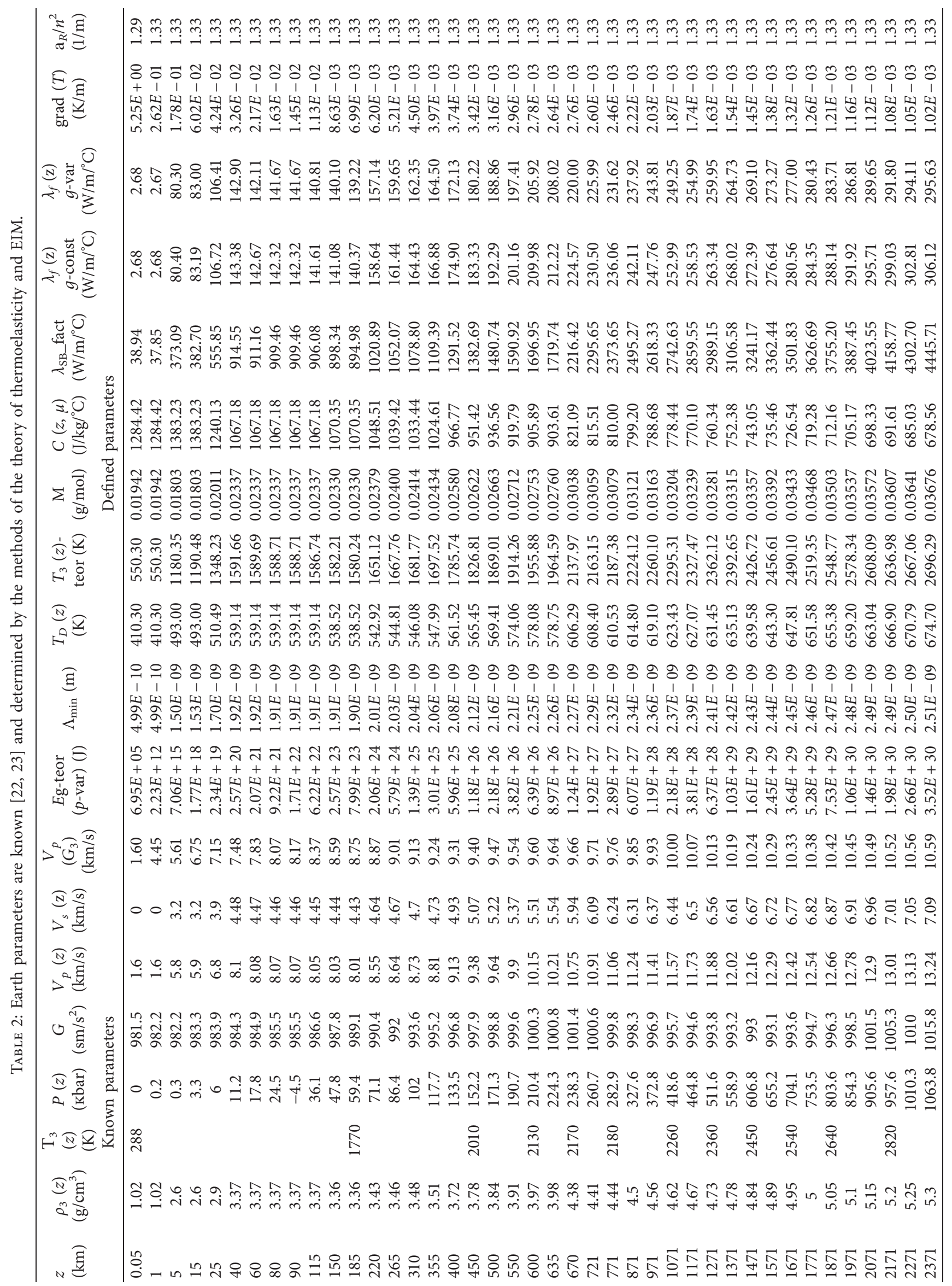




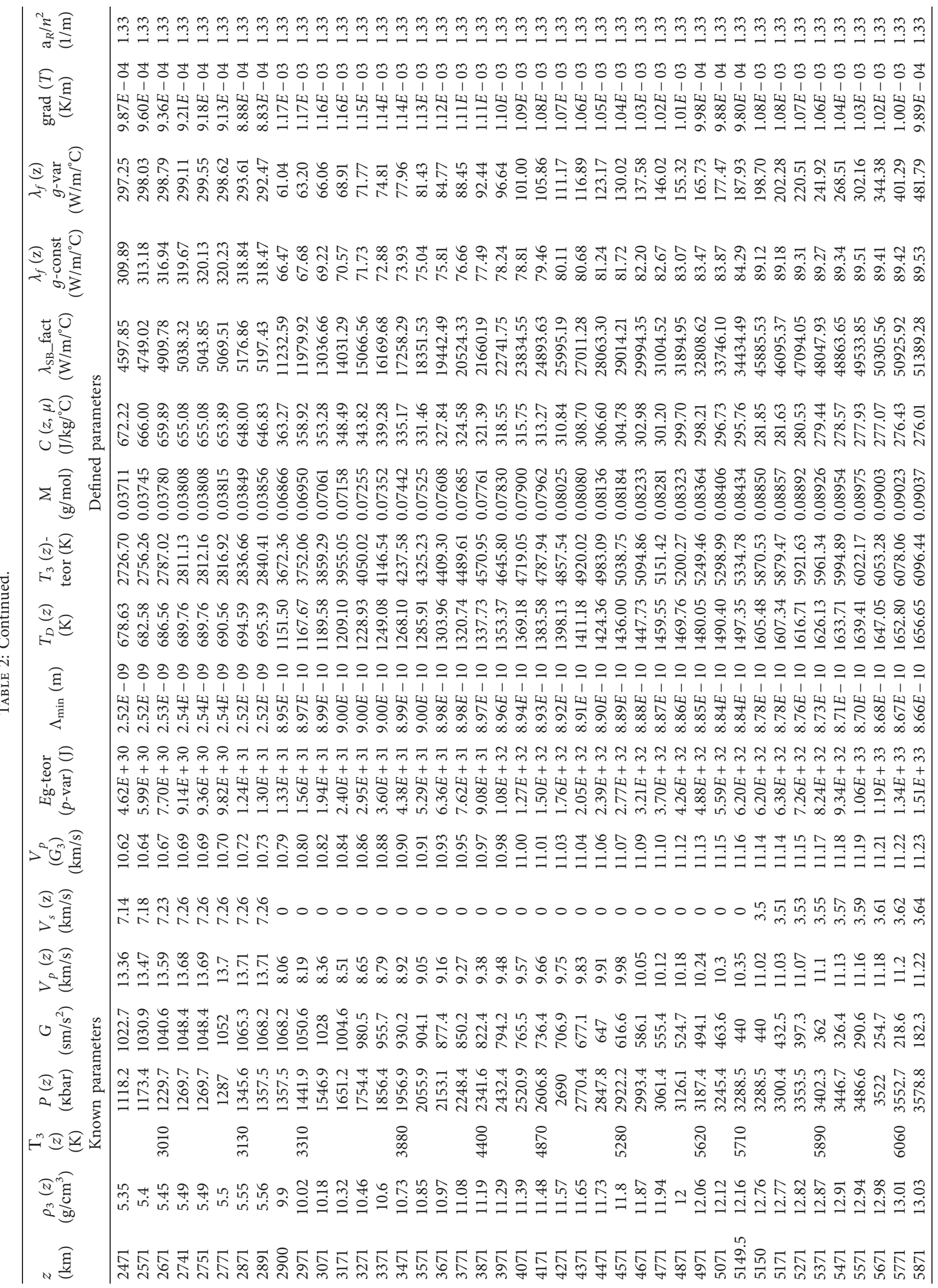




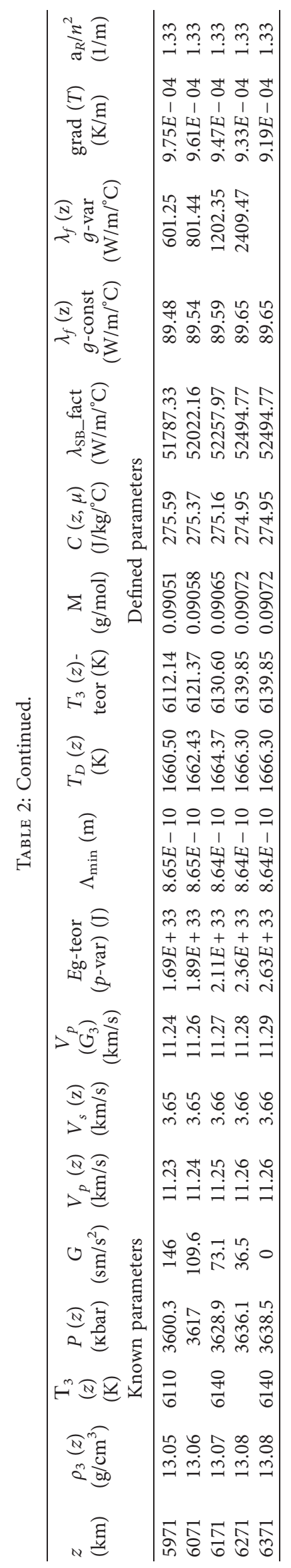




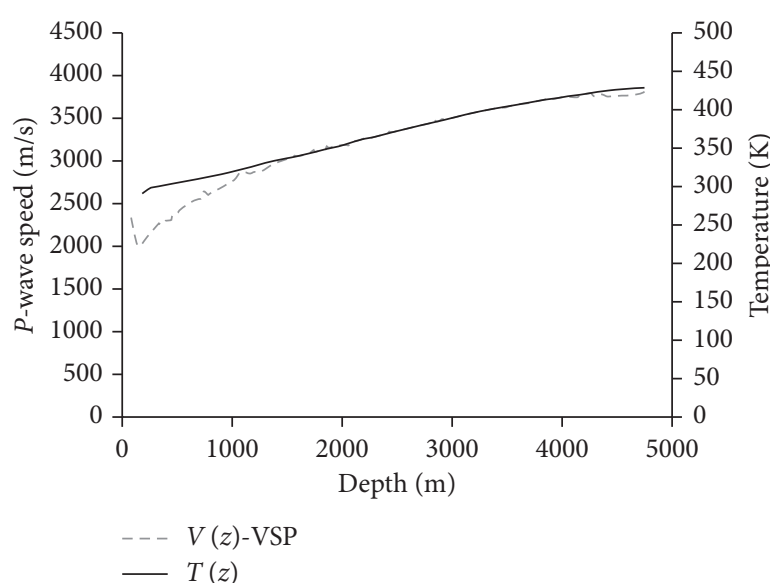

(a)

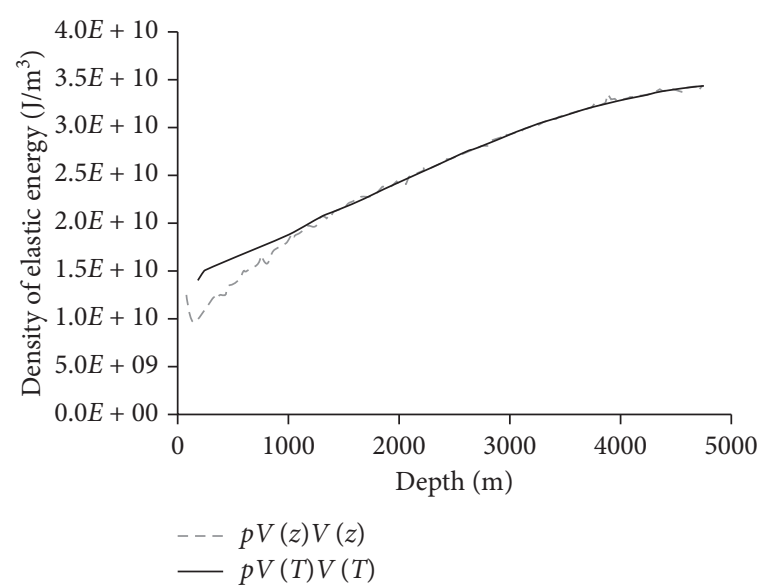

(b)

Figure 3: Characteristics: (a) the average velocity $V(z)$ of the $P$-wave and temperature $T(z)$; (b) volume density $\rho V_{p}^{2}(z)$, no elastic and thermal energy $\rho V_{p}^{2}(T)$, according to equation (6) in the GM (geological medium). According to the VSP (vertical seismic profiling) and thermometry, geophysical studies of well number 10 of Sentyanivska Square.

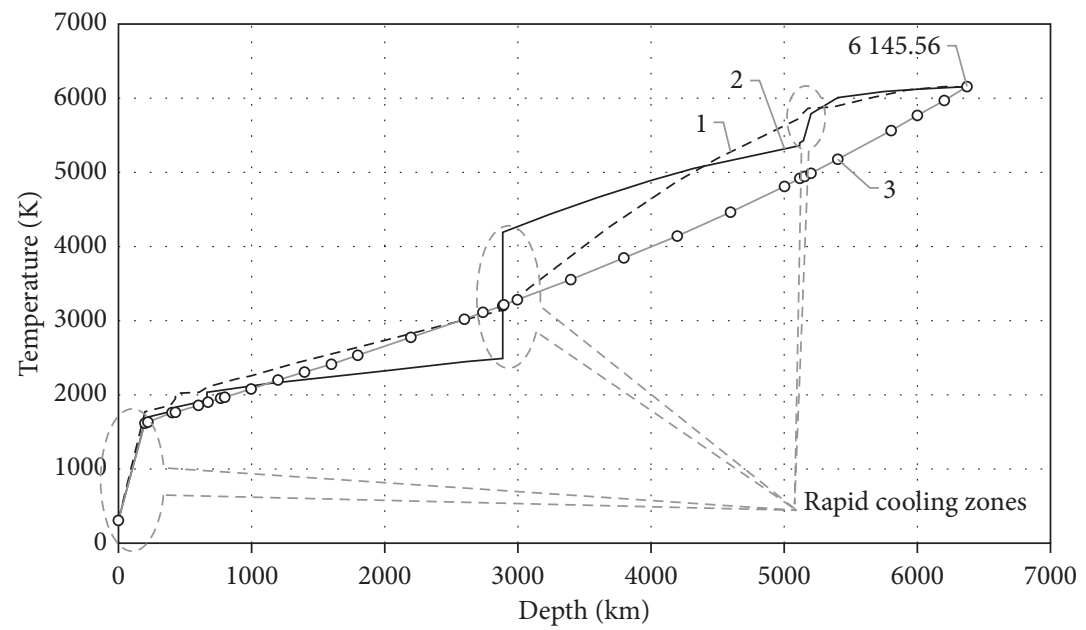

FIgURE 4: Characteristics of the temperature distribution in the Earth are determined by 1, authors in [22], and 2, by equations (7), and 3, by equation (7), for average density $\rho(z)=\rho_{0}+\chi \cdot z$.

TABLE 3: Geophysical parameters of the planets of the Solar System [25].

\begin{tabular}{lcccccccccccc}
\hline Object & $\mathrm{M}(\mathrm{kg})$ & $U(\mathrm{~J})$ & $F_{0}^{*}\left(\mathrm{~W} / \mathrm{m}^{2}\right)$ & $\ln (\mathrm{M})$ & $A(\%)$ & $\ln (\mathrm{J})$ & $\ln \left(N_{\min }\right)$ & $\ln \left(N_{\max }\right)$ & $R(\mathrm{~km})$ & $T_{\max }(\mathrm{K})$ & $T_{\min }(\mathrm{K})$ & $T_{\text {core }}^{* *}(\mathrm{~K})$ \\
\hline 1 & 2 & 3 & 4 & 5 & 6 & 7 & 8 & 9 & 10 & 11 & 12 \\
Pluto & $1.30 E+22$ & $4.51 E+27$ & 0.87 & 50.92 & 0.5 & 29.45 & 28.27 & 29.77 & 1500 & 48 & 33 & 1190 \\
Moon & $7.36 E+22$ & $1.25 E+29$ & 1360 & 52.65 & 0.12 & 37.10 & 34.70 & 38.77 & 1737 & 390 & 95 & 1427 \\
Mercury & $3.28 E+23$ & $1.77 E+30$ & 9228 & 54.15 & 0.142 & 39.69 & 33.26 & 41.46 & 2439 & 700 & 90 & 2204 \\
Mars & $6.40 E+23$ & $4.83 E+30$ & 586 & 54.82 & 0.17 & 37.59 & 36.46 & 38.64 & 3393 & 293 & 170 & 3315 \\
Venus & $4.88 E+24$ & $1.58 E+32$ & 2586 & 56.85 & 0.67 & 40.23 & 43.48 & 43.82 & 6051 & 800 & 735 \\
Land & $5.98 E+24$ & $2.25 E+32$ & 1360 & 57.05 & 0.367 & 39.70 & 38.02 & 40.53 & 6378 & 343 & 183 & 6273 \\
Uranus & $8.70 E+25$ & $1.25 E+34$ & 3.7 & 59.73 & 0.51 & 36.47 & 35.81 & 37.18 & 24300 & 76 & 54 & 8315 \\
Neptune & $1.03 E+26$ & $1.70 E+34$ & 1.5 & 59.90 & 0.41 & 35.62 & 36.30 & 37.02 & 25050 & 72 & 60 & 8400 \\
Saturn & $5.68 E+26$ & $2.14 E+35$ & 15 & 61.60 & 0.47 & 39.69 & 39.45 & 41.27 & 60400 & 134 & 85 & 16650 \\
Jupiter & $1.90 E+27$ & $2.02 E+36$ & 50.3 & 62.81 & 0.52 & 41.23 & 41.33 & 42.19 & 71400 & 155 & 125 & 27760 \\
Sonce & $1.99 E+30$ & $2.28 E+41$ & & 69.77 & & & & & 695700 & 15000000 \\
\hline
\end{tabular}

${ }^{*} F_{0}$ is the solar constant and $A$ is the albedo of the planet [25]. ${ }^{* *}$ Data obtained from [26]. 


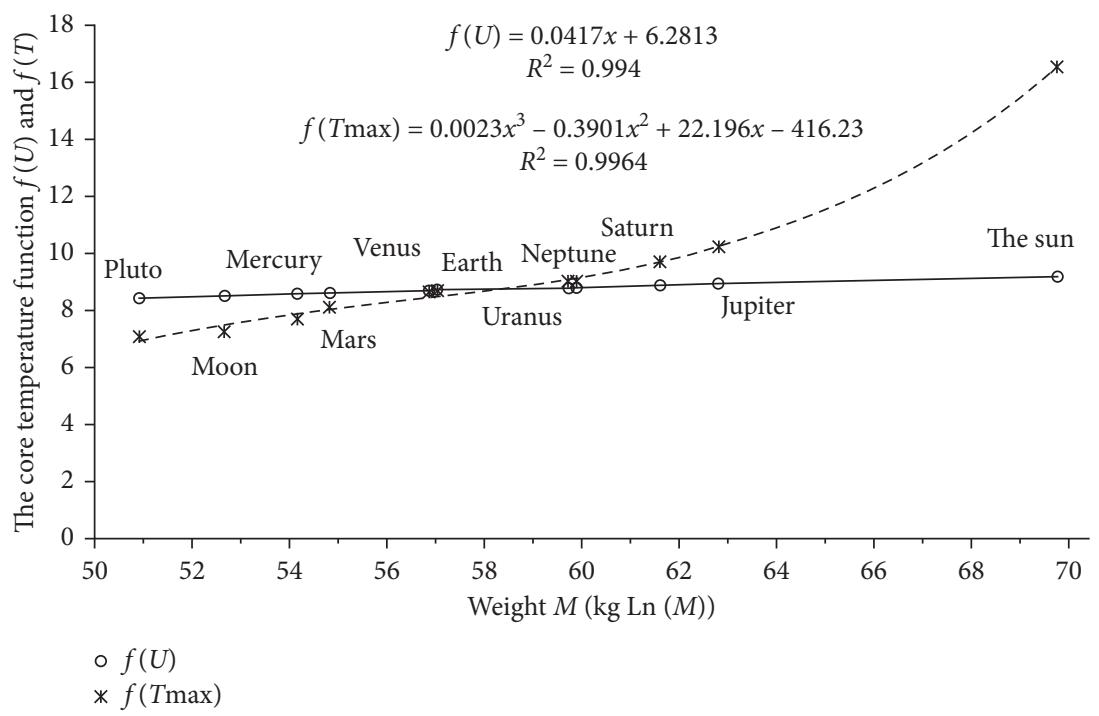

FIGURE 5: Qualitative logarithmic characteristics of functions (polynomial approximations) of the temperature of the nucleus of the Solar System planets. Depending on their mass: $f\left(T_{\max }\right)=\ln \left(T_{\max }\right)$, according to the known hypothetical values of the temperature of the nucleus; $f(U)$, analogous to equation (7).

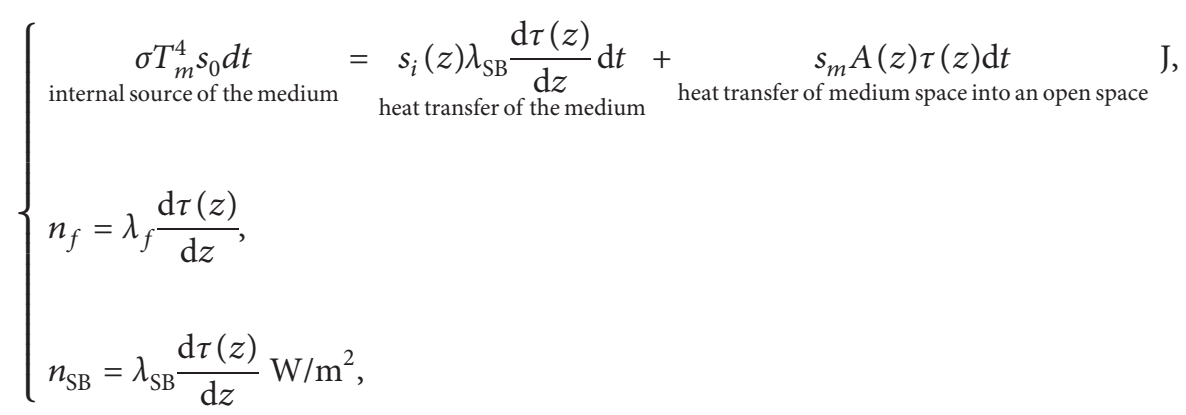

where $z$ is the coordinate from the Earth's surface to its center, $\mathrm{m} ; T_{m}$ is the radiant source temperature (for example, ISE of internal core), $\mathrm{K} ; \sigma$ is the Stefan-Boltzmann coefficient, $\mathrm{W} / \mathrm{m}^{2} / \mathrm{K}^{4} ; s_{0}=s_{i}=s_{m}$ is the single surface, $1 \mathrm{~m}^{2}$; $n_{\mathrm{SB}}\left(T_{0}\right)=\sigma \mathrm{T}_{0}^{4}$ is the heat flux density of infrared waves at temperature $\quad T_{0}=288 \mathrm{~K},\left(T_{m}=6140 \mathrm{~K}\right), \quad \mathrm{W} / \mathrm{m}^{2}$; $\lambda_{\mathrm{SB}}=\left(16 n^{2} \sigma / 3 \alpha_{R}\right) \tau^{3}$ is the coefficient of radiation thermal conductivity of the environment $[15,27], \mathrm{W} /(\mathrm{m} \cdot \mathrm{K}) ; \alpha_{R}=$ $\left(16 \sigma / 3 n^{2} \lambda_{\mathrm{SB}}\right) \tau^{3}=\left(16 \sigma / 3 \lambda_{f}\right)\left(n_{f} / n_{\mathrm{SB}}\right) \tau^{3}[28,29]$ is the average Rossland coefficient of energy absorption of radiation rays through which the given rays penetrate, $\mathrm{m}^{-1} ; n$ is the refractive index of the medium by electromagnetic waves; $\tau$ is the temperature of the substance of the Earth, $\mathrm{K} ; m(z)$ is the mass of environment, and $(\mathrm{d} \tau / \mathrm{d} z)=\operatorname{grad}(\tau)$ is the conductive temperature gradient in the $\mathrm{GE}, \mathrm{K} / \mathrm{m}$;

$$
\begin{aligned}
\lambda_{f}(z) & =\frac{\partial^{3} U}{\partial \tau \cdot \partial z \cdot \partial t}=\frac{\partial^{3}[C(z) \cdot m(z) \cdot \tau(z)]}{\partial \tau \cdot \partial z \cdot \partial t} \\
& =C \rho \frac{\partial^{3}}{\partial \tau \cdot \partial z \cdot \partial t}[w(z) \cdot \tau]=8 \pi C \rho z \frac{\partial z}{\partial t}
\end{aligned}
$$

$$
\begin{aligned}
& =8 \pi(C)\left(\frac{G}{g(z) \cdot w_{0}}\right)\left(z \frac{\mathrm{d} z}{\mathrm{~d} t}\right)=8 \pi C \rho z V_{p} \\
& =8 \pi\left(\frac{3 R}{\mu_{3}}\right)\left(\frac{G}{g(z) \cdot w_{0}}\right)\left(\lambda_{\min }(z) V_{p}(z)\right),
\end{aligned}
$$

which is coefficient of conductive thermal conductivity of the environment $\mathrm{W} /(\mathrm{m} \cdot \mathrm{K}) ; U$ is the internal energy of the environment, J; $C=3 R$ which is the heat capacity of the environment, $\mathrm{J} /(\mathrm{mol} \cdot \mathrm{K}), R=8.314510 \mathrm{~J} /$ Mole $/ \mathrm{K}$ which is the universal gas constant; $(\mathrm{d} z / \mathrm{d} t)=V_{p}$ is the velocity of the $P$ wave in the environment, $\mathrm{m} / \mathrm{s} ; \rho=\left(G /\left(g \cdot w_{0}\right)\right)=\left(m / w_{0}\right)$ which is the environment density, $\mathrm{N} /\left(\mathrm{m} / \mathrm{c}^{2}\right) / \mathrm{m}^{3}=\mathrm{kg} / \mathrm{m}^{3}$ $\left(\mathrm{mol} / \mathrm{kg} / \mathrm{m}^{3}\right) ; C \rho=3 R \mu$ which is the entropy density of the environment [30], $\mathrm{J} /\left(\mathrm{kg} \cdot \mathrm{K} \cdot \mathrm{m}^{3}\right)$, where $\mu$ is the number of moles in $1 \mathrm{~m}^{3}$ (or $\left(3 R / \mu_{3}\right)=\mathrm{C}=\left(5 / T_{3}^{4}(z) \pi\right)\left(2 \hbar / k_{B} \lambda_{3 \min }\right.$ $(z))^{3} V_{p 3}^{5}(z)$ for $\left.\mu_{3} \mathrm{~kg} / \mathrm{mol}\right) ; A(z)=\sigma \tau^{3}(z)$ which is the coefficient of heat transfer of the surface of the environment, $\mathrm{W} / \mathrm{m}^{2} / \mathrm{K} ; z=\lambda_{30}=2 \pi \hbar\left(V_{p 3} / T_{D} k_{B}\right)$ which is the minimum wavelength of the acoustic phonon in the environment, $\mathrm{m}$, where $T_{D}=290 \mathrm{~K}$ is Debye's temperature $\mathrm{SiO}_{i}$ and $V_{p 3}=$ $8000 \mathrm{~m} / \mathrm{s}$ at a depth of $50 \mathrm{~km}$; and $s_{0}=4 \pi R_{C}^{2}, s_{i}(z)=$ $4 \pi z^{2}, s_{m}=4 \pi R_{3}^{2}$. The problem is considered for 
$s_{0}=s_{i}=s_{m}=1 \mathrm{~m}^{2} ; V_{m}=22.4139695$ which is the molar volume, $1 / \mathrm{mol}$.

The solution of the system of equations (13) will be performed for the following initial and boundary conditions: $\tau_{0}\left(z_{0}=0 \mathrm{~m}\right)=T_{0}=288 \mathrm{~K}$ and $\tau_{m}\left(z_{m}=6371008 \mathrm{~m}\right)=$ $T_{m}=6140 \mathrm{~K}$.

The first equation of the system of equations (13) has [29] an integral function of the form

$$
\begin{aligned}
\int \mathrm{d} z= & \frac{\lambda_{\mathrm{SB}}}{\sigma} \int \frac{\mathrm{d} \tau(z)}{T_{m}^{4}-\tau^{4}(z)}+\mathrm{C}_{0} \longrightarrow z=\frac{\lambda_{\mathrm{SB}}}{\sigma 4 T_{m}^{3}}\left[\ln \left|\frac{T_{m}+\tau(z)}{T_{m}-\tau(z)}\right|\right. \\
& \left.+2 \operatorname{arctg}\left(\frac{\tau(z)}{T_{m}}\right)\right]+C_{0} .
\end{aligned}
$$

The solution (15) of the system of equations (13) is the exact solution integral function for the dependence of $z$ from the temperature distribution in the depths of the Earth in the model.
For $\quad \ln \left|\left(T_{m}+\tau(z)\right) /\left(T_{m}-\tau(z)\right)\right| \gg\left(1 / 4 T_{m}^{3}\right) \operatorname{arctg}(\tau$ $\left.(z) / T_{m}\right)$, we obtain a simplified analytical solution of the temperature function from depth:

$$
\begin{aligned}
\frac{\left\{\exp \left[\left(z-C_{0}(z)\right)\left(\sigma 4 T_{m}^{3} / \lambda_{\mathrm{SB}}(z)\right)\right]-1\right\}}{\left\{\exp \left[\left(z-C_{0}(z)\right)\left(\sigma 4 T_{m}^{3} / \lambda_{\mathrm{SB}}(z)\right)\right]+1\right\}} T_{m}= & \tau(z), \\
C_{0}(z)= & z-\frac{\lambda_{\mathrm{SB}}(z)}{\sigma 4 T_{m}^{3}} \\
& \cdot\left[\ln \left|\frac{T_{m}+\tau(z)}{T_{m}-\tau(z)}\right|\right],
\end{aligned}
$$

where $C_{0}(z)$, the constant, is defined as the analytical depth for each pair of parameters $\tau(z), z$; the radial thermal conductivity parameter $\lambda_{\mathrm{SB}}(z)$ of the Earth's geological environment was determined by the following equation:

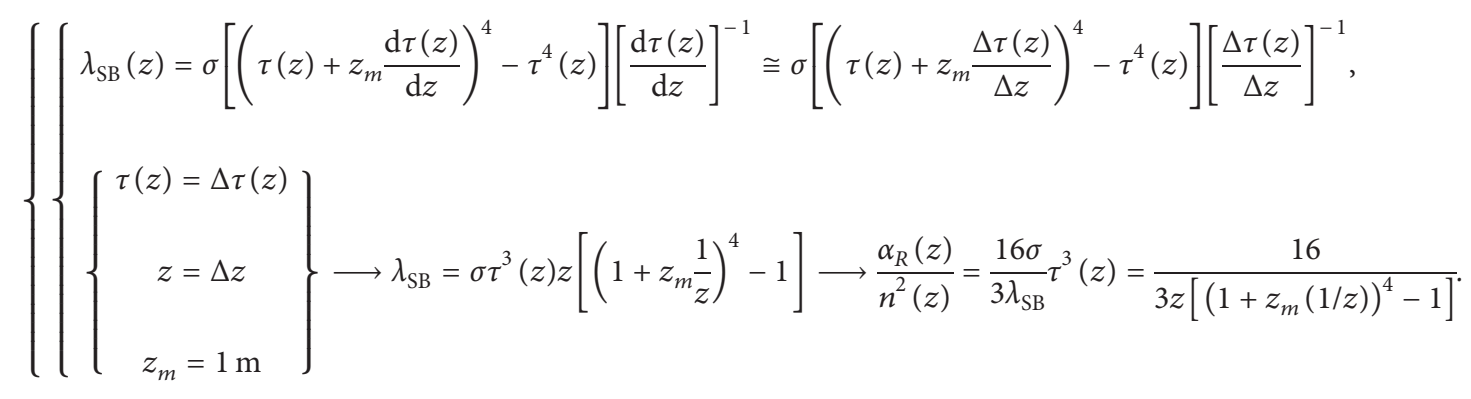

In Figures 6-11, the results of research equation (16) are presented. Characteristics of distributions of radiation thermal conductivity $\lambda_{\mathrm{SB}}$ and absorption $\alpha_{R}$ are determined by known data on the distribution of Earth's temperature $\tau(z)$ [14] by formulas (17).

Figure 6 shows the characteristics of the temperature profiles known [22] and determined by equation (7), $T(z)$ - teor, and equation (16), as well as the Rosseland coefficient with the refractive index determined by equation (17).

Figure 7 shows the characteristics of the radial, $\lambda_{\mathrm{SB}}(z)$, and conductive, $\lambda_{f}(z)$, heat transfer profiles from the center of the Earth to its surface, as well as their relationship. Moreover, the parameter $\lambda_{f}(z)$ is defined for constant acceleration $g(z)=$ const and variable actual $g(z)=$ var acceleration of gravity.

Experimental laboratory studies of iron conductivity for geobaric conditions of the Earth at a depth of $3000 \mathrm{~m}$ are given in the paper [32], where, for conditions $112 \mathrm{GPa}$, $3000 \mathrm{~K}$, the authors determined the value of heat conductivity $20 \div 80 \mathrm{~W} / \mathrm{m} / \mathrm{K}$, shown in Figure 8 .

The thermal conductivity in Figure 7 has a max value $67.7 \mathrm{~W} / \mathrm{m} / \mathrm{K}$. The graph of the distribution of the heat content of the Earth's substance is shown in Figure 9.
Figure 10 shows the characteristics of the acoustic wavelength distribution and the heat capacity of the Earth's substance. The frequency of oscillations of elementary objects of the Earth's substance was determined by the equation $\omega_{3}(z)=\left(V_{p 3}(z) / \lambda_{3 \min }(z)\right)$ [16]. The characteristic of the frequency of oscillations of atoms and molecules in the propagation of the Earth's $P$-waves is shown in Figure 10.

The temperature on the Earth's surface due to the heat flux of the Sun.

To build the temperature characteristics of the Earth's surface, taking into account the thermal energy of the Sun, the authors determined the total thermal conductive power in the atmosphere of sunlight rays and the temperature of their absorbed photons, by the following equation [27]:

$$
N_{\mathrm{C}-3}=0.5 S_{3}\left(n_{3-\mathrm{C}} k_{R}\right)=0.5 S_{3}\left(\frac{16 \sigma_{0}}{3} T_{\mathrm{C}-3}^{3} \frac{\mathrm{d} T_{A}}{\mathrm{~d} z}\right)=2.766 \cdot 10^{13} \mathrm{~W} \text {, }
$$

with density $\left(0.108 \mathrm{~W} / \mathrm{m}^{2}\right)$, where $T_{C}=273.15+5870$ which is the temperature of the Sun surface, $\mathrm{K}$, and $\left(\mathrm{d} T_{A} / \mathrm{d} z\right)$ is the temperature gradient of the Earth's atmosphere, $\mathrm{K} / \mathrm{m}$ $(0.0056 \mathrm{~K} / \mathrm{m})[33] . T_{\mathrm{C}-3}=T_{C} \sqrt[4]{R_{C}^{2} 1 / L_{\mathrm{C}-3}^{2}}=400 \mathrm{~K}$ which is the 


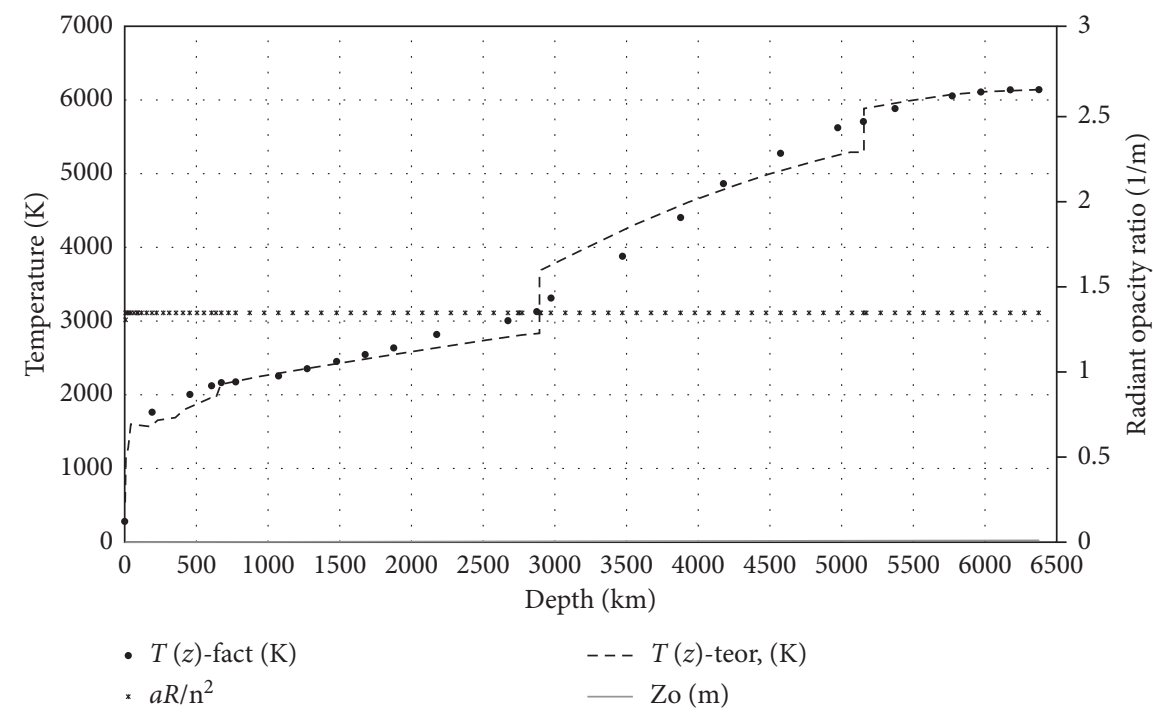

Figure 6: Characteristics of temperature profiles in the bowels of the Earth, where $\tau(z)$ is constructed by equation $(16)$, and $\left(\alpha_{R}(z) / n^{2}(z)\right)$ by equation (17). In [31] for aluminum and iron, the defined parameter was 1.3. $\alpha_{R}(z)$ is the coefficient of Rosseland absorption of electromagnetic waves by the medium; $n(z)$ is the refractive index of electromagnetic waves in the medium.

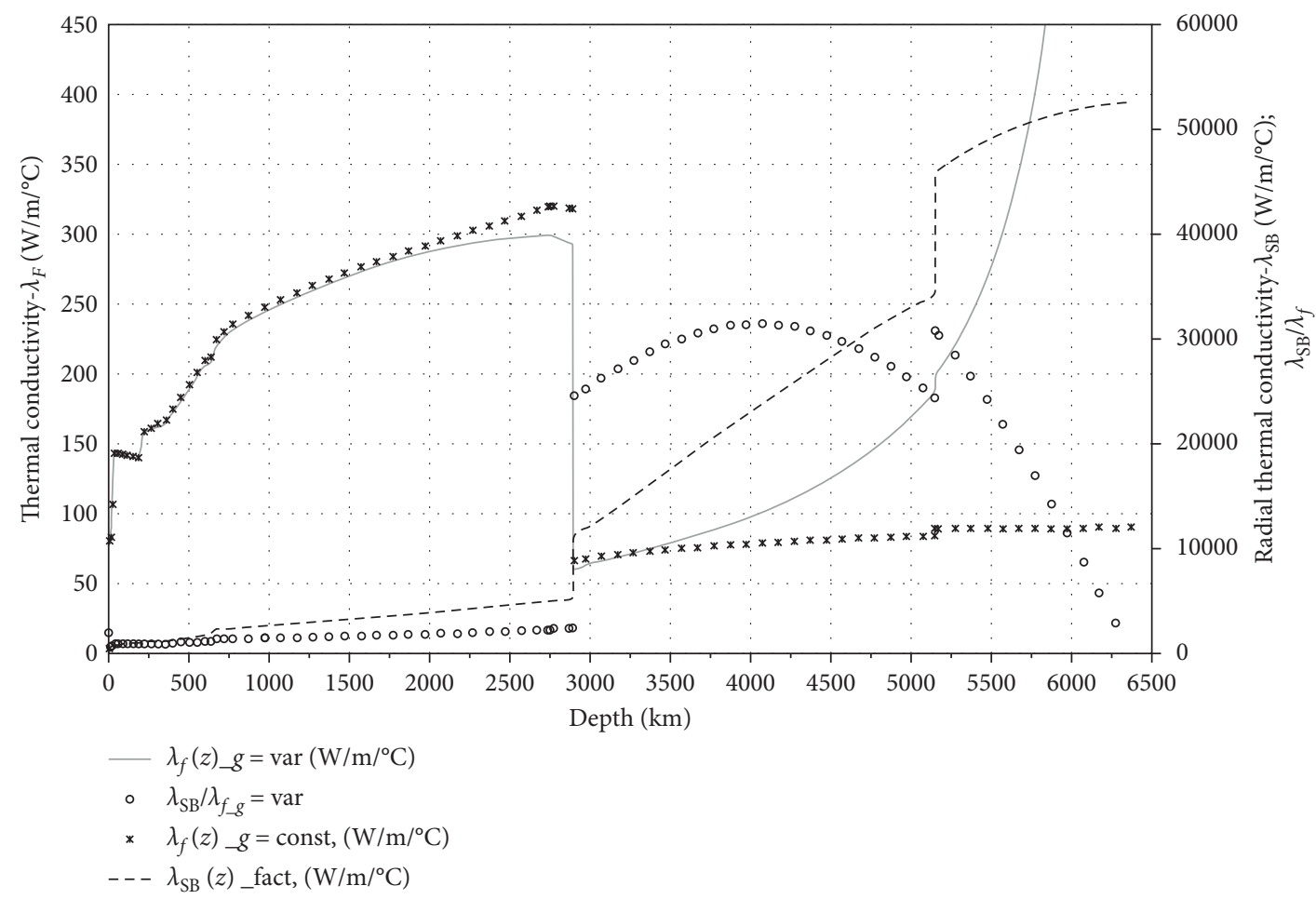

FIGURE 7: Characteristics of the profiles of radial $\lambda_{\mathrm{SB}}(z)$ and conductive $\lambda_{f}(z)$ thermal permeability of the Earth's matter from the center to its surface, $\lambda_{\mathrm{SB}}(z)_{-}$fact is the thermal conductivity of EM waves; $\lambda_{f}(z)_{-} g=$ var is the conductive thermal conductivity with variable acceleration of gravity; $\lambda_{f}(z)_{-} g=$ const is the conductive thermal conductivity with constant acceleration of gravity; $\left(\lambda_{\mathrm{SB}} / \lambda_{f-} g\right)=$ var is the ratio of the thermal conductivity of EM waves to the conductive thermal conductivity at variable acceleration of gravity. 


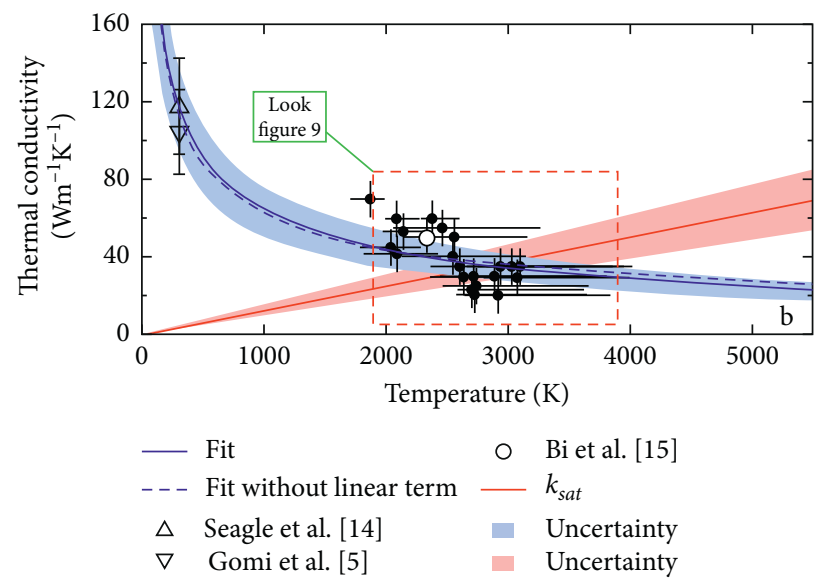

FIGURE 8: High temperature transport properties of Fe. Thermal conductivity temperature dependence at 112 GPa. 33 experiments obtained model fit and a $20 \%$ uncertainty envelope are in blue; matching model without a linear term: dashed line. Present data are solid circles, and data derived from prior electrical resistivity measurements are open symbols (see Figure 3 ). Red band is the minimum thermal conductivity assuming resistivity saturation [32].

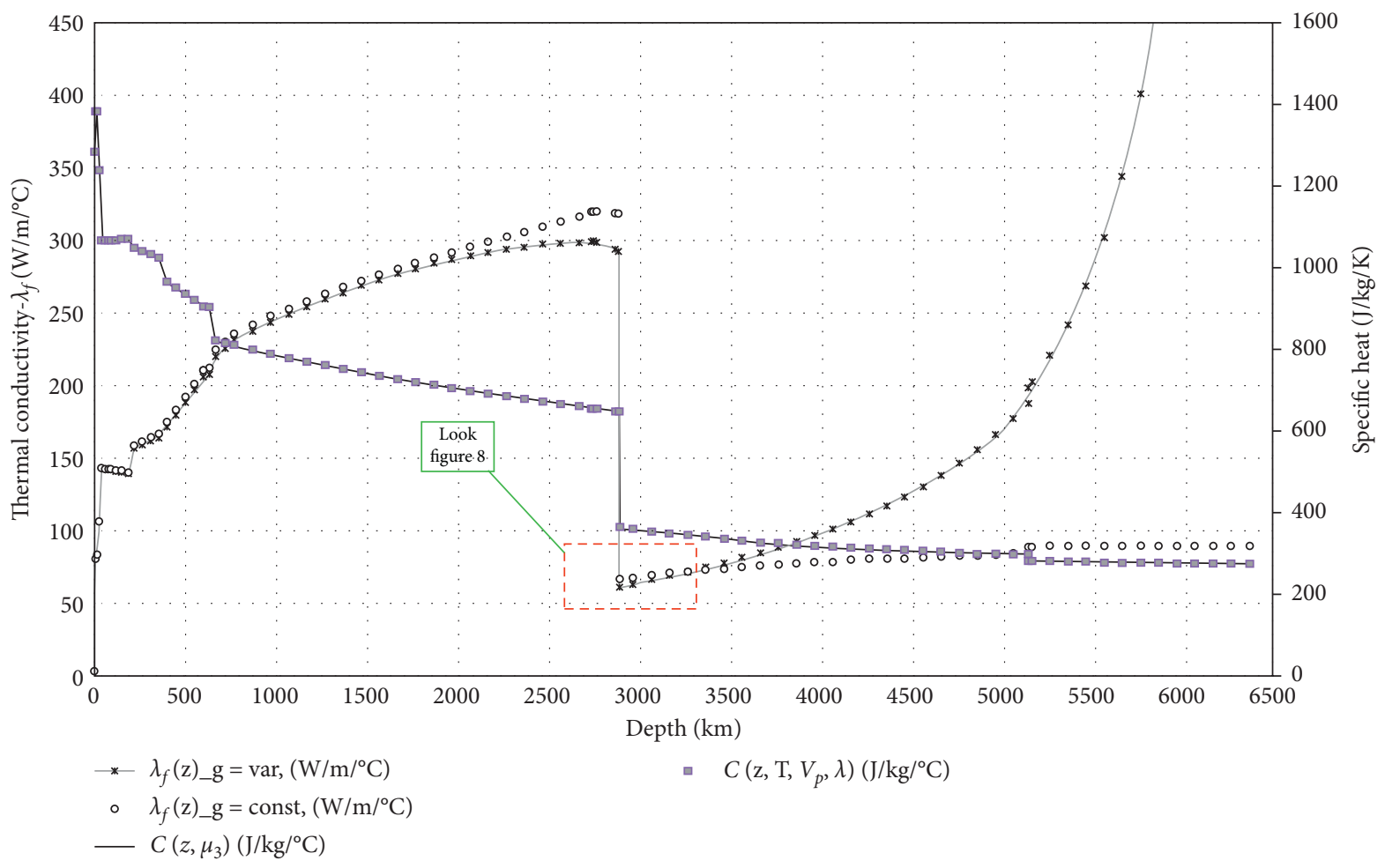

FiguRE 9: Characteristics of thermal conductivity of the Earth's matter for different characteristics of gravitational accelerations: $g(z)=$ const, $z \in\left[0 \div R_{3}\right], \quad g(z)=$ var, $z \in\left[0 \div R_{3}\right]$, and heat capacity, determined by different formulas: $C(z, \mu)=\left(3 R / \mu_{3}\right)$; $C\left(z, T, V_{p}, \lambda_{\min }\right)=\left(5 / T_{3}^{4}(z) \pi\right)\left(2 \hbar / k_{B} \lambda_{3 \min }(z)\right)^{3} V_{p 3}^{5}(z)$.

determined temperature of the solar photons on the Earth's surface. $R_{C}=0.695$ million $\mathrm{km}$ which is the radius of the Sun; $L_{\mathrm{C}-3}=149.6$ million $\mathrm{km}$ which is the average distance from the Sun to Earth; $0.5 S_{3}$ is the Earth's surface, $\mathrm{m}^{2}$, which absorbs the thermal energy of the Sun; $n_{3-\mathrm{C}}=163.3 \mathrm{~W} / \mathrm{m}^{2}$ which is the density of the heat flux from the Sun on the Earth's surface; and $k_{R}$ is an unknown coefficient of absorption of short infrared waves by the Earth's atmosphere, which can be determined from equation (18).

Model of the Earth with exogenous and endogenous radiative heat fluxes represents the model of the process of sequential heating-cooling of the Earth's layers [34].

The authors propose a geothermal model of the Earth (1) in a thermodynamic formulation by a system of equations 


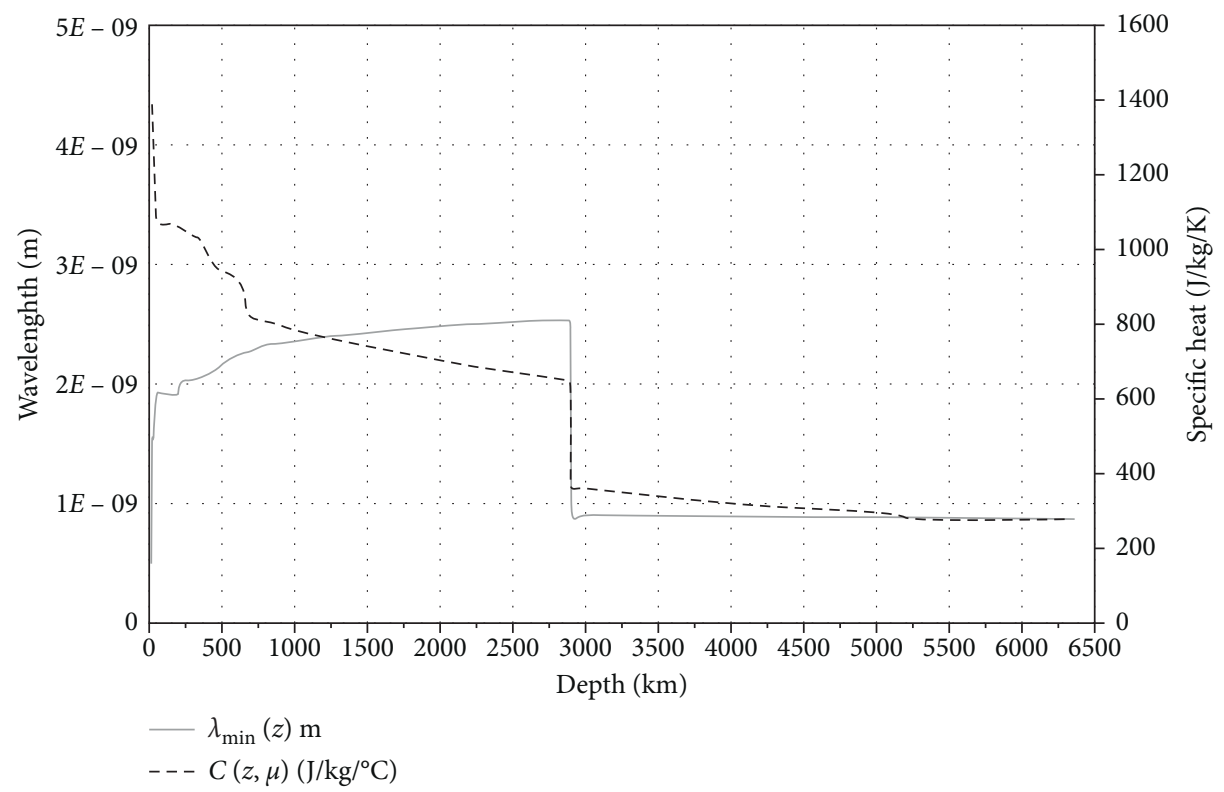

Figure 10: Characteristics of the length distribution of acoustic waves and the heat capacity of the Earth's matter.

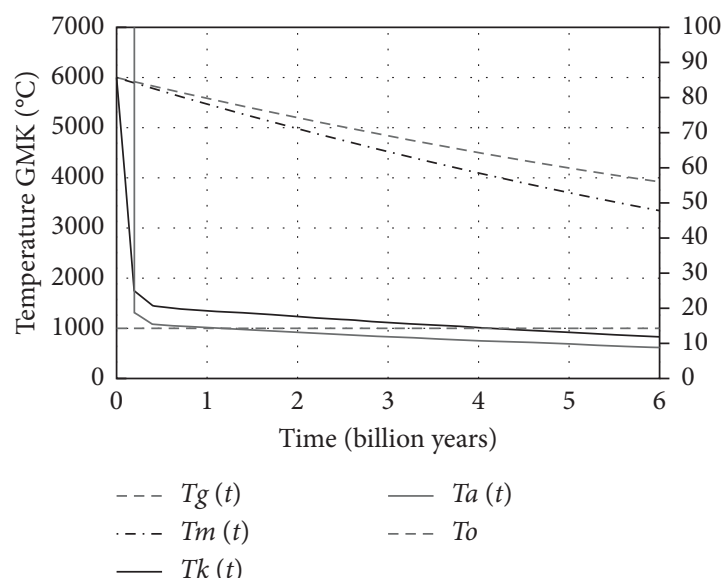

(a)

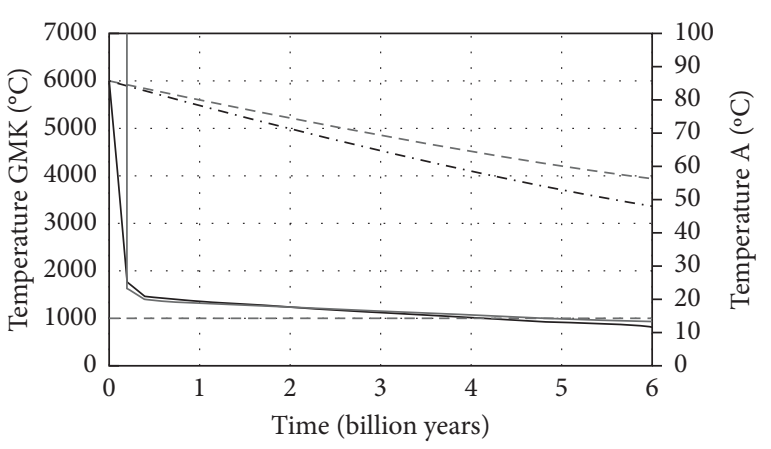

$--\operatorname{Tg}(t)$

$-T a(\mathrm{t})$

...- $\operatorname{Tm}(t)$

$---T o$

$-\operatorname{Tk}(t)$

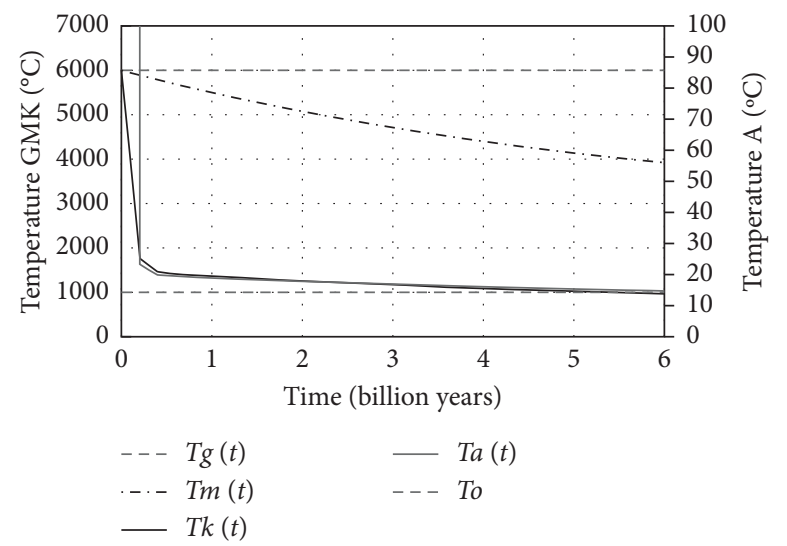

(c)

Figure 11: Characteristics of the values of the temperature of the nucleus, mantle, crust, and Earth's atmosphere, depending on the time: (a) pure cooling of the Earth; (b) cooling of the Earth with heating from the exogenous heat source; (c) heating-cooling of the Earth from an endogenous source and heating from an exogenous thermal source.
(a) $\left\{\begin{array}{l}N_{3-F}=0 \\ N_{C-3}=0\end{array}\right.$,
(b) $\left\{\begin{array}{l}N_{3-F}=0 \\ N_{C-3} \neq 0\end{array}\right.$
(c) $\left\{\begin{array}{l}N_{3-F} \neq 0 \\ N_{C-3} \neq 0\end{array}\right.$ 
for successive processes of heating and cooling of its phases (inner core, outer core and mantle, crust, and atmosphere) in the form internal:

$$
\begin{cases}N_{3-\mathrm{F}} \mathrm{d} t=C_{G} \mathrm{~d} \tau_{G}+A_{G} \tau_{G} \mathrm{~d} t, & \text {-internal core; } \\ A_{G} \tau_{G} \mathrm{~d} t=C_{M} \mathrm{~d} \tau_{M}+A_{M} \tau_{M} \mathrm{~d} t, & \text {-external core + mantle; } \\ A_{M} \tau_{M} \mathrm{~d} t=C_{K} \mathrm{~d} \tau_{K}+A_{K} \tau_{K} \mathrm{~d} t, & \text {-crust; } \\ \left(A_{K} \tau_{K}+N_{\mathrm{C}-3} \mathrm{~d} t\right)=C_{A} \mathrm{~d} \tau_{A}+A_{A} \tau_{A} \mathrm{~d} t, & \text {-atmosphere; }\end{cases}
$$

where $N_{3-\mathrm{F}} \mathrm{d} t$ is the total thermal energy of ISE, J; $N_{\mathrm{C}-3} \mathrm{~d} t$ is the total thermal energy of electromagnetic waves from the Sun on the Earth's surface, $\mathrm{J} ; C_{G} \mathrm{~d} \tau_{G}$ is the energy of heating the inner core of the Earth, $\mathrm{J} ; \tau_{G}$ is the current excess temperature of the inner core above the temperature of the magma, $\mathrm{K} ; A_{G} \tau_{G} \mathrm{~d} t$ is the energy of cooling the surface of the inner core, J; $C_{M} \mathrm{~d} \tau_{M}$ is the energy of heating magma, J; $C_{K} \mathrm{~d} \tau_{K}$ is the energy of heating the core, J; $\tau_{M}$ is the current excess temperature of the magma on its surface above the crust temperature, $\mathrm{K} ; A_{M} \tau_{M} \mathrm{~d} t$ is the cooling energy by a magmatic phase for the heating of the atmosphere, $\mathrm{J} ; \tau_{K}$ is the current excess temperature of the crust on the surface of the Earth above the temperature of the atmosphere, $\mathrm{K}$; $\left(A_{K} \tau_{K}+N_{C}\right) \mathrm{d} t$ is the energy that heats the atmosphere from the Earth and the Sun, J; $A_{K} \tau_{K} \mathrm{~d} t$ is the energy of cooling the crust, $\mathrm{J} ; C_{A} \mathrm{~d} \tau_{A}$ is the energy of heating the atmosphere, $\mathrm{J} ; \tau_{A}$ is the current high temperature of the atmosphere on the Earth's surface above the temperature of the open physical space, $\mathrm{K} ; A_{A} \tau_{A} \mathrm{~d} t$ is the energy that is devoted by the atmosphere to the open physical space, J; $A_{G}=\left(N_{3-\mathrm{F}} / T_{G 0}\right)$ is the coefficient of heat transfer of the surface of the inner core Earth, $\mathrm{J} /{ }^{\circ} \mathrm{C} / \mathrm{sec} ; A_{M}=\left(N_{3-\mathrm{F}} / \bar{T}_{M}\right)$ is the coefficient of heat transfer of the surface of the mantle, $\mathrm{J} /$ ${ }^{\circ} \mathrm{C} / \mathrm{sec} ; A_{K}=\left(N_{3-\mathrm{F}} / \bar{T}_{K}\right)$ is the coefficient of heat transfer of the Earth's crust surface, $\mathrm{J} /{ }^{\circ} \mathrm{C} / \mathrm{sec} ; A_{A}=\left(N_{3-\mathrm{F}} / \bar{T}_{A}\right)$ is the coefficient of heat transfer of atmosphere, $\mathrm{J} /{ }^{\circ} \mathrm{C} / \mathrm{sec} ; \mathrm{C}_{G}=$ $\mathrm{c}_{G} m_{G}+\mathrm{c}_{M} m_{M}+\mathrm{c}_{K} m_{K}+\mathrm{c}_{A} m_{A}$ is the entropy of all phase states of the Earth substance, $\mathrm{J} /{ }^{\circ} \mathrm{C} ; C_{M}=\mathrm{c}_{M} m_{M}+\mathrm{c}_{K} m_{K}+$ $\mathrm{c}_{A} m_{A}$ is the entropy of magma, crust, and atmosphere, $\mathrm{J} /{ }^{\circ} \mathrm{C}$; $C_{K}=\mathrm{c}_{K} m_{K}+\mathrm{c}_{A} m_{A}$ is the entropy of the crust and atmosphere, $\mathrm{J} /{ }^{\circ} \mathrm{C} ; \mathrm{C}_{A}=\mathrm{c}_{A} m_{A}$ is the entropy of the Earth's atmosphere, $\mathrm{J} /{ }^{\circ} \mathrm{C} ; T_{G 0}=6000$ is the temperature of the surface of the inner core, ${ }^{\circ} \mathrm{C} ; \bar{T}_{K}=0.5\left(T_{K}+T_{K 0}\right)=0.5 \cdot(1320+$ $10)=665$ which is the average temperature of the crust between the temperatures of the inner and outer surfaces, ${ }^{\circ} \mathrm{C}$; $\bar{T}_{M}=0.5 \cdot\left(T_{R}+T_{M}\right)=0.5 \cdot(1320+6000)=3660$ which is the average temperature of the magmatic phase, ${ }^{\circ} \mathrm{C} ; \bar{T}_{A}=$ 14.2 which is the average temperature of the Earth's atmosphere, ${ }^{\circ} \mathrm{C} ; E_{3}=N_{3-\mathrm{F}} \cdot t_{3}$ which is the total heat energy spent on heating the Earth during its geological existence time, $t_{3} ; m_{G}=\rho_{G} \cdot(4 / 3) \pi R_{G}^{3}$ which is the mass of internal core, $\mathrm{kg} ; m_{M}=\rho_{M} \cdot(4 / 3) \pi\left[\left(R_{3}-\Delta L_{K}\right)^{3}-R_{G}^{3}\right]$ is the mass of outer core and mantle, $\mathrm{kg} ; m_{K}=\rho_{K} \cdot(4 / 3) \pi\left[\left(R_{3}\right)^{3}-\right.$ $\left.\left(R_{3}-\Delta L_{K}\right)^{3}\right]$ which is the mass of Earth crust, kg; $m_{A}=$ $5.3 \cdot 10^{18}$ which is the given mass of atmosphere $[35,36], \mathrm{kg}$; $\rho_{G}, \rho_{M}, \rho_{A}$ are the average densities of the inner core, the outer core and the magma, the crust, and the Earth's atmosphere, respectively, $\mathrm{kg} / \mathrm{m}^{3} ; \quad N_{3-\mathrm{F}}=A_{K} \tau_{K}=\eta_{3-f}$. $S_{3}=\eta_{3-f} \cdot 4 \pi R_{3}^{2}$ which is the given total thermal power of conductive heating-cooling on the surface of the Earth's crust, $\mathrm{W} ; \eta_{3-f}=0.087$ which is the average square density of the thermal conductive flux on the surface of the crus, $\mathrm{W} / \mathrm{m}^{2}$.

The solution of the system of differential equations (19) is a function of the form

$$
\left\{\begin{array}{l}
\tau_{G}(t)=\left(T_{G 0}-\frac{N_{3-\mathrm{F}}}{A_{G}}\right) e^{-\omega_{G} t}+\frac{N_{3-\mathrm{F}}}{A_{G}}, \\
\tau_{M}(t)=\left(T_{G 0}-\frac{A_{G}}{A_{M}} \cdot \tau_{G}(t)\right) e^{-\omega_{M} t}+\tau_{G}(t) \frac{A_{G}}{A_{M}}, \\
\tau_{K}(t)=\left(T_{G 0}-\frac{A_{M}}{A_{K}} \cdot \tau_{M}(t)\right) e^{-\omega_{K} t}+\tau_{M}(t) \frac{A_{M}}{A_{K}}, \\
\tau_{A}(t)=\left(T_{G 0}-\frac{N_{\mathrm{C}-3}}{A_{A}}-\frac{A_{K}}{A_{A}} \cdot \tau_{K}(t)\right) e^{-\omega_{A} t}+\frac{N_{\mathrm{C}-3}}{A_{A}}+\frac{A_{K}}{A_{A}} \cdot \tau_{K}(t),
\end{array}\right.
$$

where $\left\{\omega_{G}=A_{G} \cdot\left[C_{G} m_{G}+C_{M} m_{M}+C_{K} m_{K}+C_{A} m_{A}\right]^{-1}\right.$;

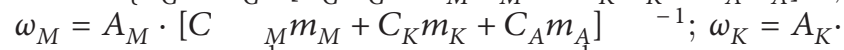
$\left[C_{K} m_{K}+C_{A} m_{A}\right]^{-1} ; \omega_{A}=A_{A} \cdot\left[C_{A} m_{A}\right]^{-1}$, which is the heat exchange frequency, and $s^{-1}$ is found by the method of successive integration of temperature functions for stationary mode of heat transfer. The solution of the system of differential equations (19) is executed for the given initial and boundary conditions of the stationary regime, given in Table 4.

\section{Results and Discussion}

The investigation of the geothermal model of the Earth with endogenous and exogenous heat fluxes by equations (20) is fulfilled for the following conditions:

(1) Lack of ISE and heat flux from the Sun (pure cooling)

(2) Lack of ISE and the presence of heat flux from the Sun (cooling the Earth and heating the atmosphere and the Earth's surface from the Sun)

(3) Presence of ISE and heat flux from the Sun (realheating-cooling)

(4) The individual influence of random variations in the increase of the activity of the Sun and the reduction of the heat transfer of the atmosphere to $50 \%$

Substitution of values from Table 4 into the system of equations (20) allowed to construct temporal characteristics of the temperature values of the inner core, $\operatorname{Tg}(t)$, the inner core and the mantle, the crust, and the Earth's atmosphere, which are shown in Figure 11.

The value of temperature on the Earth's surface, as shown in Figure 12, shows the individual influence of arbitrary variations (increase) in the solar power and (decrease) the heat transfer of the atmosphere by $50 \%$.

3.1. Analysis of Results. Function of deterministic probability (FDP) also suggests a hypothesis about ISE [12, 37], which is based on two principles: first, there is a joint action 
Table 4: Specified initial, boundary, and defined geophysical parameters of the Earth.

\begin{tabular}{|c|c|c|c|}
\hline Geophysical parameters & Marking formula & Value & $\begin{array}{l}\text { Unit of } \\
\text { measure }\end{array}$ \\
\hline \multicolumn{4}{|l|}{ Known parameters } \\
\hline Earth's existence time ( 4.5 billion years) & $\sim t_{3}$ & $1.42 \cdot 10^{17}$ & s \\
\hline The Earth's own gravitational energy & $\widetilde{\mathrm{E}}_{G 3}(z)$ & $2.23945 \cdot 10^{3}$ & $\mathrm{~J}$ \\
\hline Total power of radiation ISE & $N_{3-\mathrm{SB}}$ & $1.86 \cdot 10^{17}$ & $\mathrm{~W}$ \\
\hline Total power of conductive heating of the Earth & $N_{3-F}^{3-F}$ & $4.44 \cdot 10^{13}$ & $\mathrm{~W}$ \\
\hline $\begin{array}{l}\text { The total power of conductive heating of the atmosphere by short infrared waves from } \\
\text { the Sun }\end{array}$ & $N_{C-3}$ & $2.77 \cdot 10^{13}$ & $\mathrm{~W}$ \\
\hline Maximum density in the center of the Earth & $\rho_{3-m}$ & 13290 & $\mathrm{~kg} / \mathrm{m}^{3}$ \\
\hline The average radius of the Earth & $R_{3}$ & 6371008.8 & $\mathrm{~m}$ \\
\hline $\begin{array}{l}\text { Average density of conductive heat flux on the surface of the lithosphere at the present } \\
\text { time }\end{array}$ & $\eta_{3-f}$ & 0.087 & $\mathrm{~W} / \mathrm{m}^{2}$ \\
\hline $\begin{array}{l}\text { Average density of heat flux of infrared waves on the surface of the lithosphere (depth } \\
\text { of } 50 \mathrm{~m} \text { ) at present }\end{array}$ & $\eta_{3-\mathrm{SB}}$ & 364.46 & $\mathrm{~W} / \mathrm{m}^{2}$ \\
\hline Earth mass (average density $5510 \mathrm{~kg} / \mathrm{m}^{3}$ ) & $M_{3}$ & $5.969 \cdot 10^{24}$ & $\mathrm{~kg}$ \\
\hline The mass of the atmosphere & $m_{A}$ & $5.3 \cdot 10^{18}$ & $\mathrm{~kg}$ \\
\hline Average atmospheric temperature near the Earth's surface & $T_{0}$ & 14.2 & ${ }^{\circ} \mathrm{C}$ \\
\hline Average temperature of the lithosphere at a depth of $50 \mathrm{~m}$ & $T_{K 0}$ & 10 & ${ }^{\circ} \mathrm{C}$ \\
\hline The surface temperature of the mantle at a depth of $50 \mathrm{~km}$ & $T_{K}$ & 1320 & ${ }^{\circ} \mathrm{C}$ \\
\hline Temperature of the surface of the inner core of the Earth & $\mathrm{T}_{G 0}$ & 6000 & ${ }^{\circ} \mathrm{C}$ \\
\hline The average specific heat of the atmosphere & $C_{A}$ & 1005 & $\mathrm{~J} / \mathrm{kg} /{ }^{\circ} \mathrm{C}$ \\
\hline \multicolumn{4}{|l|}{ Defined parameters } \\
\hline The Earth's own gravitational energy & $\mathrm{E}_{G 3}(z)$ & $2.65 \cdot 10^{33}$ & $\mathrm{~J}$ \\
\hline $\begin{array}{l}\text { The mass of the inner core of the Earth (radius } 1455 \mathrm{~km} \text {, average density } \\
12657.8 \mathrm{~kg} / \mathrm{m}^{3} \text { ) }\end{array}$ & $m_{G}$ & $1.633 \cdot 10^{23}$ & $\mathrm{~kg}$ \\
\hline Mass of mantle and outer core (average density $5876.4 \mathrm{~kg} / \mathrm{m}^{3}, 1455 \div 6321 \mathrm{~km}$ ) & $m_{M}$ & $3.26 \cdot 10^{24}$ & $\mathrm{~kg}$ \\
\hline The mass of crust (thickness $50 \mathrm{~km}$, density $2850 \mathrm{~kg} / \mathrm{m}^{3}$ ) & $m_{K}$ & $8.64 \cdot 10^{22}$ & $\mathrm{~kg}$ \\
\hline Average temperature of the Earth's magmatic phase & $\overline{\mathrm{T}}_{M}^{\wedge}$ & 3660 & ${ }^{\circ} \mathrm{K}$ \\
\hline Average temperature of the solid phase of the Earth & $\overline{\mathrm{T}}_{K}$ & 665 & ${ }^{\circ} \mathrm{K}$ \\
\hline Average atmospheric temperature on the Earth's surface & $\overline{\mathrm{T}}_{\mathrm{A}}^{\wedge}$ & 14.2 & ${ }^{\circ} \mathrm{K}$ \\
\hline Average specific heat of internal core & $C_{G}$ & 275 & $\mathrm{~J} / \mathrm{kg} /{ }^{\circ} \mathrm{C}$ \\
\hline Average specific heat of the outer core and mantle of the Earth & $C_{M}$ & 630 & $\mathrm{~J} / \mathrm{kg} /{ }^{\circ} \mathrm{C}$ \\
\hline Average specific heat of measles & $C_{K}$ & 1285 & $\mathrm{~J} / \mathrm{kg} /{ }^{\circ} \mathrm{C}$ \\
\hline Total internal energy of heating the Earth & $E_{3}=t_{3} N_{3-F}$ & $6.297 \cdot 10^{30}$ & J \\
\hline The total energy dissipated by the Earth in an open physical space & $E E_{3-\mathrm{SB}}=t_{3} N_{3-\mathrm{SB}}$ & $2.635 \cdot 10^{34}$ & $\mathrm{~J}$ \\
\hline General gravitational energy of the Earth & $E_{G P}=U_{G}=0.5 E_{3-C}$ & $2.661 \cdot 10^{33}$ & $\mathrm{~J}$ \\
\hline Total internal energy of the inner core & $E_{G}$ & $1.652 \cdot 10^{29}$ & $\mathrm{~J}$ \\
\hline Total internal energy of the mantle and the outer core & $E_{M}$ & $6.075 \cdot 10^{30}$ & $\mathrm{~J}$ \\
\hline Total internal energy of crust & $E_{K}$ & $8.01 \cdot 10^{28}$ & $\mathrm{~J}$ \\
\hline Total internal energy of the atmosphere & $E_{A}$ & $1.64 \cdot 10^{29}$ & $\mathrm{~J}$ \\
\hline $\begin{array}{l}\text { The coefficient of heat transfer on the surface of the inner core to the inner core and } \\
\text { mantle }\end{array}$ & $A_{G}$ & $7.396 \cdot 10^{9}$ & $\mathrm{~J} / \mathrm{s} /{ }^{\circ} \mathrm{C}$ \\
\hline Coefficient of heat transfer of the mantle to its solid phase & $A_{M}$ & $1.212 \cdot 10^{10}$ & $\mathrm{~J} / \mathrm{s} /{ }^{\circ} \mathrm{C}$ \\
\hline Coefficient of heat transfer of solid phase to atmosphere & $A_{K}$ & $6.673 \cdot 10^{10}$ & $\mathrm{~J} / \mathrm{s} /{ }^{\circ} \mathrm{C}$ \\
\hline Coefficient of heat transfer of the atmosphere into space & $A_{A}$ & $3.125 \cdot 10^{12}$ & $\mathrm{~J} / \mathrm{s} /{ }^{\circ} \mathrm{C}$ \\
\hline Temperature of physical space & $T_{\mathrm{SB}}^{A}$ & $-269(4.15)$ & ${ }^{\circ} \mathrm{C}(\mathrm{K})$ \\
\hline Core cooling frequency & $\omega_{g}$ & $3.34 \cdot 10^{-18}$ & $\mathrm{c}^{-1}$ \\
\hline The cooling frequency of the external core and mantle & $\omega_{M}^{y}$ & $5.59 \cdot 10^{-18}$ & $\mathrm{~s}^{-1}$ \\
\hline Crust cooling frequency & $\omega_{K}$ & $6.00 \cdot 10^{-16}$ & $\mathrm{~s}^{-1}$ \\
\hline Atmosphere cooling frequency & $\omega_{\mathrm{a}}$ & $1.198 \cdot 10^{-9}$ & $\mathrm{~s}^{-1}$ \\
\hline
\end{tabular}

of the laws of conservation, modification, transfer, and packaging of energy in a physical point (PP); second, there is physical space, as a system of physical points (SPP), at each point of which the joint action of the laws of conservation, modification, transfer, and packaging of energy is carried out.

The dimensionless FDP of space is represented in the following form:
$\left\{\begin{array}{l}E=K+U=A^{2}(x), \\ \frac{K U}{E^{2}}=\ln A^{-2}(x),\end{array}\right.$

where $\left(\mathrm{E}(x) / E_{0}\right)=A^{2}(x)$ is the value of the total energy at a point, which is distributed in space, $ч$, of a particular physical system with given energy $E_{0}=$ const; 


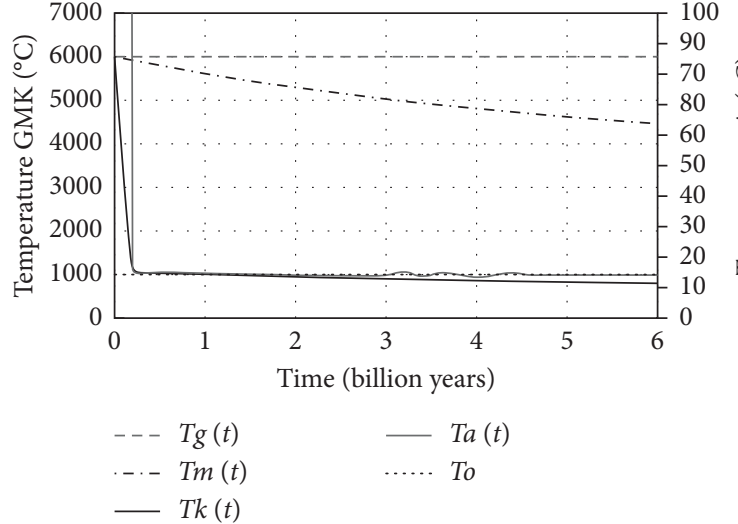

(a)

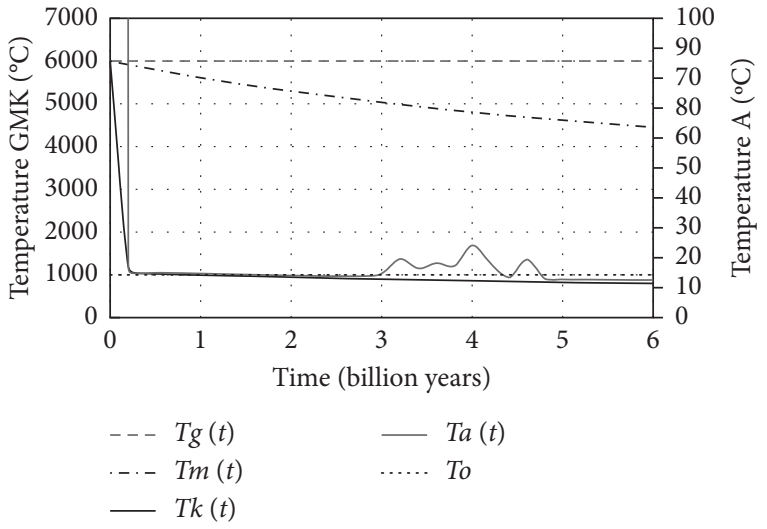

(b)

FIGURE 12: Characteristics of the values of atmospheric temperature, depending on the increase in the activity of the Sun and the accidental decrease in the heat transfer of the atmosphere to 50\%: (a) variations in the increase of the heat flux of the Sun on the Earth's surface to 50\%; (b) variations in the reduction of the heat transfer of the atmosphere to $50 \%$.

$K=\left(K(x) / E_{0}\right) \cdot U=\left(U(x) / E_{0}\right)$ is the relative units of kinetic and potential energies at a point that are also distributed in the physical system (furthermore, we accept const $=1$ ).

The system of equations (21) defines the values of potential and kinetic energy at each point of the physical system by the formulas

$$
\left\{\begin{array}{l}
U(x)=A^{2}(x) \cdot\left(\frac{1}{2} \pm \sqrt{\frac{1}{4}-\ln \frac{1}{A^{2}(x)}}\right), \\
K(x)=A^{2}(x) \cdot\left(\frac{1}{2} \mp \sqrt{\frac{1}{4}-\ln \frac{1}{A^{2}(x)}}\right) .
\end{array}\right.
$$

For the Solar System, the energy characteristics are shown in Figures 13 and 14.

According to Zone III, where the external influence allows an increase in potential or kinetic energy, the Earth's own gravitational potential energy is determined from the system of equations (22).

3.2. Analysis of Energy Relations for Planets of the Solar System. Figure 14 testifies that (a) all planets of the Solar System are located at point B in Figure 13 (energy packaging law); (b) the total energy of each planet is determined by the system of equations (21) in its center and in orbit (24); and (c) the own total gravitational energy of each planet is divided into potential gravitational and thermoelastic in Zones I and II.

Example 1. (1) SPP-«Sun-Earth», (2) SPP-«Earth».

$$
\begin{aligned}
E_{\mathrm{C}-3} & =\gamma \frac{M_{\mathrm{C}} m_{3}}{L_{\mathrm{C}-3}}=5.3 \cdot 10^{33} \mathrm{~J} ; \\
K_{3} & =\frac{m_{3} V^{2}}{2}=0.5 E_{\mathrm{C}-3}=2.65 \cdot 10^{33} \mathrm{~J} \\
U_{3} & =E_{\mathrm{C}-3}-K_{3}=0.5 E_{\mathrm{C}-3}, \\
E_{G} & =\widetilde{K}_{3}=\widetilde{U}_{3} ; \\
\widetilde{E}_{3} & =\widetilde{K}_{3}+\widetilde{U}_{3}=U_{3}=2.65 \cdot 10^{33} \mathrm{~J} .
\end{aligned}
$$

The Earth's own gravitational total energy provided by $\rho=\rho_{0}+\chi \cdot z$ is determined by the integral: $U_{3}=2.65 \cdot 10^{33} \mathrm{~J}$.

From Figure 13, it is evident that the internal kinetic (thermal) energy of the planet reaches the total gravitational energy in the center, and the potential energy disappears, as is the acceleration of gravity.

The geothermal model of the Earth with endogenous and exogenous heat fluxes suggests an increase in the temperature of the bowels of the planet with an unchanging total gravitational energy with increasing depth, as well as the existence of the following geophysical sequential mechanisms triggered by the ISE thermal density when approaching the center of the Earth.

The boundary of Zone III and the whole Zone II:

(1) The existence of a solid lithosphere on the Earth's surface.

(2) Destruction-formation of a solid body of the lithosphere on the border with the mantle.

(3) Formation of the liquid phase of the Earth from different atoms and molecules, various compounds from chemical elements. 

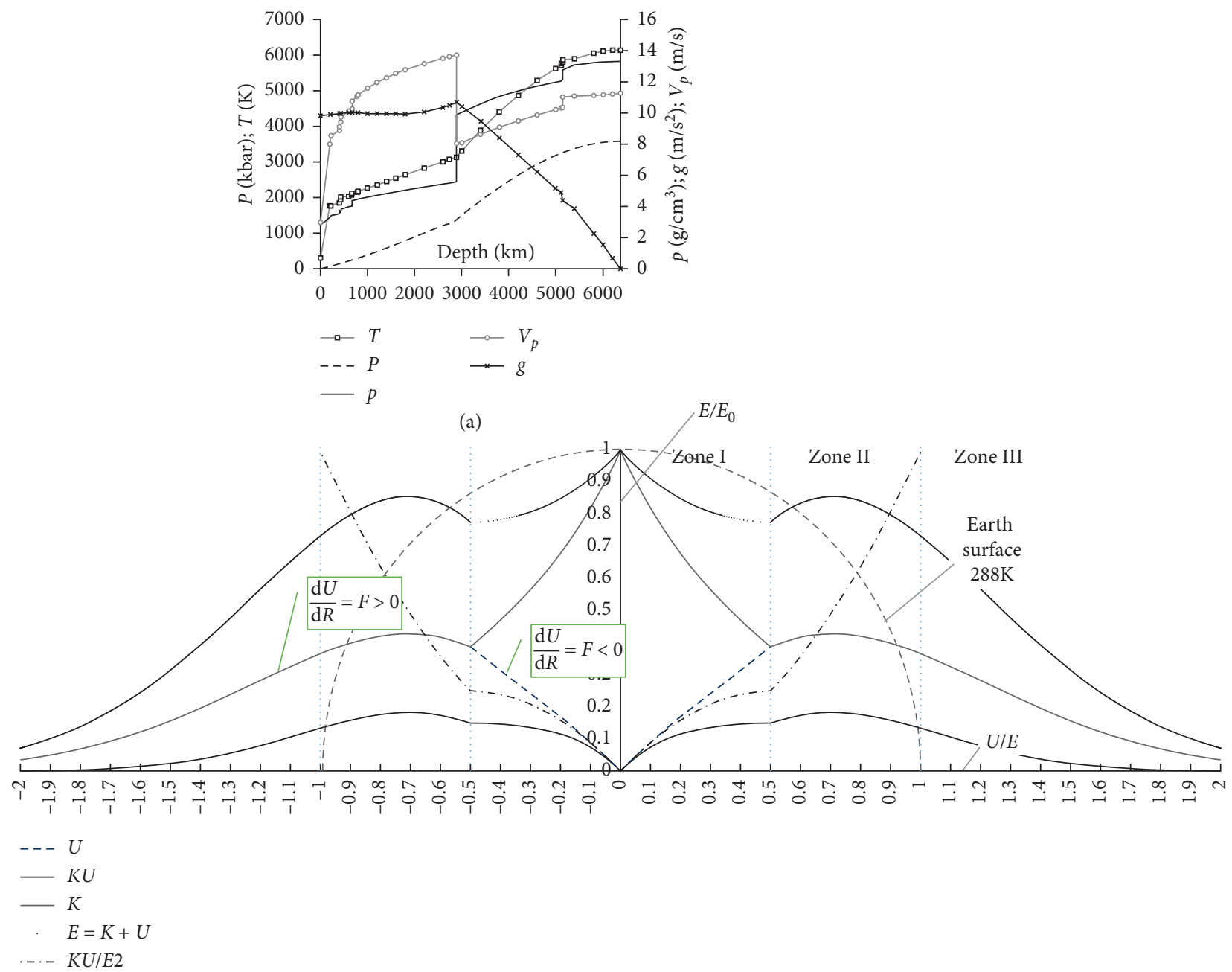

(b)

FIGURE 13: Characteristics of the function of the determined probability (FDP), planet Earth, and planets of the Solar System, as systems of physical points: (a) physical parameters of the Earth; (b) the energy characteristics of the FDP states of internal and external points of the physical system, depending on the ratio $U / E$ where $K$ is the kinetic (calorific) energy of the system, $U$ is a potential (elastic) energy of the system, $E$ is the total energy of the system, $K U$ is the transfer of the energy invariant in the system, $K U / E^{2}=\Psi^{2}$ is the phase of the energy state of the system, $E_{0}=1$ is the initial given energy in the system of physical points; $F>0$ is the gravitational compression force; $F<0$ is the gravitational tensile force.

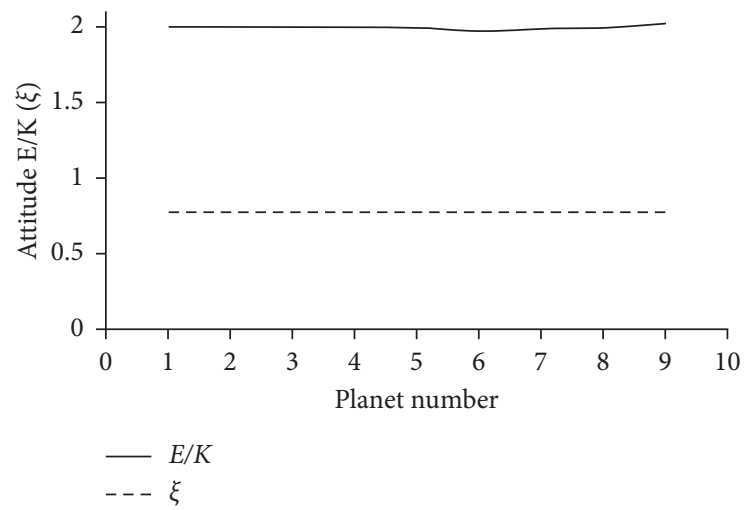

FIgURE 14: Characteristics of energy correlations of planets of the Solar System by formulas $\xi=e^{-\psi^{2}}, \psi^{2}=\left(K U / E^{2}\right), \xi=\left(E / E_{0}\right)$. 
(4) Dissociation and synthesis of atoms and molecules. Atoms of hydrogen are destroyed by the latter with increasing depth, after which sharply increases the density of matter, and the nuclei of light chemical elements (the middle of the radius of the Earth) accumulate. The nucleus of heavier elements moves to Zone I.

(5) Dissociation and synthesis of the nucleus of chemical elements (the latter, closer to the center of the Earth, the nuclei of iron break down into protons and neutrons).

(6) At the center of the Earth on the surface of a sphere with a radius of proton, the density of thermal energy reaches $\eta_{P}=\eta_{3-f-\max }\left(R_{3}^{2} / R_{P}^{2}\right)=0.35 \cdot(6371000$ $\left.{ }^{2} /\left(8.78 \cdot 10^{-16}\right)^{2}\right)=1.84287 \cdot 10^{43} \mathrm{~W} / \mathrm{m}^{2}$, and for the destruction of the proton, density of thermal energy on its surface should be equal to $1.5923 \cdot 10^{43} \mathrm{~W} / \mathrm{m}^{2}$ (the corresponding temperature of electromagnetic waves $7.26212 \cdot 10^{12} \mathrm{~K}$, and the frequency of oscillations of the De Broglie wave of the proton $2.27766 \cdot 10^{23} \mathrm{~Hz}$ [20]). The destroyed proton will create a density of heat flux $0.3 \mathrm{~W} / \mathrm{m}^{2}$ on the Earth's surface. That is, we can assume that physical conditions in the center of the Earth's core for the destruction of protons and neutrons exist. The maximum density of the heat flux recorded on the Earth's surface is $\eta_{3-f-\max }=0.35 \mathrm{~W} / \mathrm{m}^{2}$ [38]:

$$
\left\{\begin{array}{l}
E=\gamma \frac{M m}{R}, \\
K=\frac{m V^{2}}{2}, \\
U=E-K, \\
\frac{E}{K}=\frac{\gamma(M / R)}{V^{2} / 2}=2 \gamma \frac{M}{\omega^{2} R^{3}} .
\end{array}\right.
$$

3.3. Analysis of Results. Formulas (2), (4), and (5) are proposed by the author Karpenko for modeling the energy equilibrium of the joint action of heat fluxes of conductive and radiant EM waves in a geological environment.

Formula (5) for the input data provides the following solutions of temperature:

$$
\left\{\begin{array}{c}
T_{3}=273.15+10=283.15 \mathrm{~K} ; \lambda_{f}=3.5 \mathrm{~W} / \mathrm{m} \cdot \mathrm{K} ; \varepsilon=1 ; \\
z_{0}=1 \mathrm{~m} ; \alpha_{R}=1 \mathrm{~m}^{-1} ; \\
a=\frac{\lambda_{f}}{z_{0}^{2} \cdot \alpha_{R} \cdot \varepsilon \cdot \sigma}=617283950.06 \mathrm{~K}^{3} ; \\
b=11050537213 \mathrm{~K}^{4} ; \sigma \simeq 5.6704 \times 10^{-8} \mathrm{~W} / \mathrm{m}^{2} \cdot \mathrm{K}^{4} ;
\end{array}\right\}
$$

where the temperature $\widetilde{T}_{1}=283.15 \mathrm{~K}$ characterizes the heating temperature of the geological environment by electromagnetic IR waves, which have an absorption coefficient $\alpha_{R}=1 \mathrm{~m}^{-1}$. Temperatures $\widetilde{T}_{2}, \widetilde{T}_{3}, \widetilde{T}_{4}$ provide additional physical information, but the interpretation of these temperatures is currently unknown and requires further research.

Formula (6) is proposed by the author Karpenko to identify the energy density of Debye theory and elasticity theory, which provides important geophysical information about the physical relationships of elastic and thermodynamic parameters of the geological environment with the kinematic parameters of the $P$-wave and thermometry parameters obtained in terrestrial and downhole geophysics.

Formula (7) is derived from formula (6) for physical identification: $T_{3}\left(E_{G}\right)=T_{D}\left(E_{G}\right)$. As a result, we obtain information about the frequency of oscillations $\Omega_{\max }$ of the thermal field of the geological environment, which transmits infrared waves from the depths of the Earth to the Earth's

$$
\Longrightarrow\left\{\begin{array} { l } 
{ \widetilde { T } _ { 1 } = 2 8 3 . 1 5 \mathrm { K } ; } \\
{ \widetilde { T } _ { 2 } = 2 1 1 . 3 3 1 \mathrm { K } ; } \\
{ \widetilde { T } _ { 3 } = - 2 4 7 . 2 4 - j 3 5 1 . 2 4 \mathrm { K } ; } \\
{ \widetilde { T } _ { 4 } = - 2 4 7 . 2 4 + j 3 5 1 . 2 4 \mathrm { K } ; }
\end{array} \Longrightarrow \left\{\left|\widetilde{T}_{1}+\widetilde{T}_{2}\right|=\left|\widetilde{T}_{3}+\widetilde{T}_{4}\right|,\right.\right.
$$

surface and is observed by satellite equipment. And seismic prospecting information about $V_{s-\text { in }}, V_{p \text {-in }}$, allows you to determine the parameter $\lambda_{\min }$. Known parameters $\Omega_{\max }$ and $\lambda_{\text {min }}$ allow from equation (7) to determine the depth parameters $\mu_{3}, \rho$ of the geological environment.

Formula (8), obtained by the author Karpenko, provides information about the increasing temperature of the geological environment from the growth of gravitational (total) energy of the geological environment of the Earth depending on the depth, which is physically related to the average $P$ wave velocity at a given depth. This information is the basis for determining the total thermal capacity of a geothermal well to select the stable operation of a geothermal station by the technology of an isolated single well.

A new value of the Earth's own gravitational energy is $2.6275 \cdot 10^{33} \mathrm{~J}$, which is an order of magnitude greater than the known value $2.23945 \cdot 10^{32} \mathrm{~J}$, and which is equal to the kinetic energy of the Earth's motion in orbit around the Sun, as proved by formula (24). An important parameter in 
formula (8) is the parameter $|\sigma|=\left(\left(R_{3}-z_{m}\right) / R_{3}\right)$, which indicates the empty space in the center of mass of the Earth.

Formula (9) is obtained by the author Karpenko in [16].

The characteristic $f(U)$ in Figure 5 indicates that the maximum temperature in the center of mass of the planets has the same value, which suggests the hypothesis of a single mechanism for converting the total gravitational energy of the planet into its thermal energy, which depends on the mass of the planet. This hypothesis is tested by equation (20), which takes into account the effective capacities of endogenous and exogenous heat fluxes on the Earth's surface and shows that the presence of a heat source in the center of the Earth allows to maintain a temperature of $6000^{\circ} \mathrm{C}$.

$$
\text { The formula } \ln (T)=f(U)=\varepsilon[\sqrt{1+\ln (1}
$$

$+U) \cdot \sqrt[4]{\sqrt{1+\ln (1+U)}}] \simeq[\sqrt{1+\ln (1+W)} \cdot \sqrt[4]{\sqrt{1+\ln (1+}}$

$W)$ ] is the identification formula from equation (9), which is used to study the internal maximum temperatures of the planets of the Solar System depending on their own gravitational energy, as shown by the characteristic $f\left(T_{\max }\right)=$ $\ln \left(T_{\max }\right)$ in Figure 5. This characteristic suggests that the center of mass of each planet's maximum temperatures is almost identical. This result suggests the following hypothesis: "In the center of mass of each space object, the gravitational energy is converted into thermal energy of EM waves, the power of which depends on the mass of the object, and the maximum temperature in the center of mass of objects is the same."

The formulas $\lambda_{f}(z)=\left(\partial^{3} U /\left(\partial_{\tau} \cdot \partial_{z} \cdot \partial_{t}\right)\right)$ and $C(z)=\left(5 / T_{3}^{4}(z) \pi\right)\left(2 \hbar / k_{B} \lambda_{3 \min }(z)\right)^{3} V_{p 3}^{5}(z)$ are obtained by the author Karpenko.

Figures 6-10 using solution (16) of the system of equations (13) and (17) obtained from equation (2) and known experimental geophysical data on the temperature distribution in the center of the Earth show the characteristics of the distribution in the middle. The Earth has its thermodynamic parameters: $\lambda_{f}(z), \lambda_{\mathrm{SB}}(z), \omega_{3}(z), \lambda_{3 \min }(z)$, $C(z),\left(\alpha_{R}(z) / n^{2}(z)\right)$.

In the system of equations (19), first developed by the author Karpenko in [38], for heat transfer processes in time in multilayer media, the author investigates the thermodynamic state of the Earth in the presence and absence of a heat source in the center of the Earth and on its surface from the Sun. Studies of equation (20) have shown that the presence of an internal heat source in the center of the Earth provides a stable surface temperature of the inner core at the level of $6000^{\circ} \mathrm{C}$. And the change in heat transfer of the atmosphere significantly affects the average temperature of the Earth's surface of Figure 12(a), and to a greater extent than the fluctuations of heat from the Sun in Figure 12(b).

The system of equations (21), first developed by the authors in $[34,37,39]$, models the infinite physical space of Gauss, in which the laws act together and simultaneously: conservation, change, transfer, and packaging of energy. From this space, various micro- and macrophysical objects are formed, in particular, space objects, which have an internal energy structure, which is shown in Figure 13 with identification to the various geophysical parameters of the
Earth. The energy structure can explain the jumps, fractures, and the very characteristics of the distribution of geophysical parameters in the middle of the Earth. The main consequence of the energy analysis of gravitational energy in the middle of the Earth is the following hypothesis: "the increase in the body's own gravitational energy, $E$, from the surface to the center of mass, masses (from $3000 \mathrm{~m}$ to $6378 \mathrm{~m}$ ) of the inner masses of the electronic shells of molecules, atoms, nuclei of physicochemical elements, and quark shells of free protons and neutrons in the center of the masses, releasing their internal energy.

This hypothesis explains the origin and dissociation of nuclei, physicochemical atoms, molecules, elements, and substances of the lithosphere, and the generation of endogenous heat by planets and stars, accompanied by a change in the gravitational force from the change in potential energy by the depth of compression by internal masses (to a depth of $3000 \mathrm{~m}$ ) to the gravitational tensile force by external masses (from $3000 \mathrm{~m}$ to $6378 \mathrm{~m}$ ) of internal masses of electronic shells of molecules, atoms, nuclei of physicochemical elements, and quark shells of free protons and neutrons in the very center of the masses, releasing their inner energy."

This hypothesis explains the origin and dissociation of nuclei, physicochemical atoms, molecules, elements, and substances of the lithosphere, and the generation of endogenous heat by planets and stars.

\section{Conclusions}

The developed geothermal model of the Earth with internal and external sources of thermal energy showed the following:

(1) The absence of an internal source of thermal energy of the Earth, of arbitrary physical nature, and thermal energy of the Sun on its surface leads to a decrease in core temperature to $4500 \mathrm{~K}$ and the average Earth surface temperature to $10 \mathrm{~K}$ (Figure 11(a)) with existing atmospheric heat transfer.

(2) The absence of an internal source of thermal energy and the presence of thermal energy of the Sun on its surface leads to a decrease in core temperature to $4500 \mathrm{~K}$ and raises the temperature on the Earth's surface to the existing value of $14.2 \mathrm{~K}$ (Figure 11(b)).

(3) The presence of an internal source of thermal energy of the Earth with a value of $1,859 \cdot 10^{17} \mathrm{~W}$ and the presence of thermal energy of the Sun on its surface leads to stabilization of the core temperature at $5986.88 \mathrm{~K}$ and raises the temperature on the Earth's surface to $15^{\circ} \mathrm{C}$ (Figure $11(\mathrm{c})$ ).

(4) The established connection of the radiation heat flux with a capacity of $1.859 \cdot 10^{17} \mathrm{~W}$ and conductive heat flux with a capacity of $4.42 \cdot 10^{13} \mathrm{~W}$ is the result of one physical process, namely, the transfer of electromagnetic waves through the substance of the Earth, which arises from the work of the internal heat source 
of the Earth. That allows to determine the basic geothermal parameters of the calorific value of rocks.

(5) The energy is determined by the energy method; that is, the proper total gravitational energy of the Earth at the level $2.65 \cdot 10^{33} \mathrm{~J}$ is structured on the potential $0.5 \cdot 2.65 \cdot 10^{33} \mathrm{~J}$ and kinetic (thermal) $0.5 \cdot 2.65 \cdot 10^{33} \mathrm{~J}$ energy.

(6) The performed research studies established the following: reduction of heat transfer of the atmosphere, or increase of its specific heat capacity by $1 \%$ of emissions from dirty technologies of generation of thermal and electric energy at the level of $1.992 \cdot 10^{13} \mathrm{~W}$, which in the model increases endogenous heat of the Earth by $\left(1.992 \cdot 10^{13}\right) /\left(4.42 \cdot 10^{13}\right)$. $100 \%$ by $45 \%$, forms a thermal resonance with an increase in its temperature by $1.43 \%$ per year. Thermal resonance in the atmosphere: a higher temperature increases the water vapor in the atmosphere, which further independently increases the heat capacity and, accordingly, the temperature of the atmosphere.

\section{Data Availability}

The analyzed and generated data used to support the findings of this study are currently commercialized. Requests for data, 6 months after the publication of this article, will be considered by the corresponding author.

\section{Conflicts of Interest}

The authors declare that they have no conflicts of interest.

\section{References}

[1] V. N. Karpenko, V. M. Stasenko, A. A. Mikhalchishin, V. M. Benko, and V. L. Kushnarev, "The state and prospects of using deep wells to provide consumers with heat and electric energy," Oil and Gas Industry of Ukraine, vol. 3, pp. 39-47, 2015.

[2] C. Alimonti and E. Soldo, "Study of geothermal power generation from a very deep oil well with a wellbore heat exchanger," Renewable Energy, vol. 86, pp. 292-301, 2016.

[3] S. J. Zarrouk and H. Moon, "Efficiency of geothermal power plants: a worldwide review," Geothermics, vol. 51, pp. 142-153, 2014.

[4] "Generating power from hot dry rock (HDR) resources. Geothermal power: issues, technologies, and opportunities for research, development, demonstration, and deployment," 2010, http://www.gtherm.net/downloads/EPRI_Geothermal_ WhitePaper.pdf.

[5] S. Parmanto, "Thermodynamic optimization of downhole heat exchangers for geothermal power generation," M.S. thesis, Izmir Institute of Technology, Izmir, Turkey, 2016.

[6] V. M. Karpenko and Y. P. Starodub, "The concept of the method of energy analysis of the motion of elementary objects of the Earth's lithosphere," Visnyk Lviv un-th: Geological Series, vol. 20, pp. 3-23, 2006.

[7] V. I. Terekhov, S. V. Kalinin, and V. V. Lemanov, "Heat transfer mechanism in nanofluids: current state of the problem (review). Part 1. Synthesis and properties of nanofluids," Thermophysics and Aeromechanics, vol. 17, no. 1, 2010.

[8] J. T. Kiehl and E. T. Kevin, "Earth's annual global mean energy budget," Bulletin of the American Meteorological Society, vol. 78, pp. 197-208, 1997.

[9] “NASA Earth's energy budget poster," 2020, https://scienceedu.larc.nasa.gov/energy_budget/.

[10] K. Ya, The Radiation Field of the Earth as a Planet, Hydrometeorological Publishing House, Leningrad, Russia, 1967.

[11] A. Vasavada, D. A. Paige, and S. E. Wood, "Near-surface temperatures on mercury and the moon and the stability of polar ice deposits," Icarus, vol. 141, no. 2, pp. 179-193, 1999.

[12] V. M. Karpenko and Y. P. Starodub, "The function of deterministic probability in studies of the structure of the Earth by geophysical methods," Geoinformatics, vol. 4, pp. 31-39, 2007.

[13] V. N. Zharkov, The Internal Structure of the Earth and Planets. Elementary Introduction to Planetary and Satellite Geophysics, LLC Science and Education, Moscow, Russia, 2013.

[14] M. Born and H. Kun, Dynamic Theory of Crystal Lattices, Clarendon Press, Oxford, UK, 1958.

[15] A. Maradudin, E. Montroll, and J. Weiss, Dynamic Theory of the Crystal Lattice in the Harmonic Approximation, Mir, Moscow, Russia, 1965.

[16] V. M. Karpenko, Organization of the Automated Control System of Drilling Process on the Basis of Multi-Parameter Information Model, Institute of Modeling Problems in Energy G. E. Puhov NAS of Ukraine, Kyiv, Ukraine, 2001.

[17] L. Ya and Kratenko, General Geology: Textbook, National Mining University, Donetsk, Ukraine, 2007.

[18] M. N. Magomedov, "Self-diffusion in an iron crystal at high pressures," Physics and Technology of High Pressures, pp. 97-112, Nauka, Moscow, Russia, 2012.

[19] W. Lowrie, A Student's Guide to Geophysical Equations, Cambridge University Press, Cambridge, UK, 2011.

[20] K. A. Postnov and A. V. Zasov, Course of General Astrophysics, Physical Faculty of Moscow State University, Moscow, Russia, 2005.

[21] V. A. Magnitsky, Internal Structure and Physics of the Earth, Nedra, Moscow, Russia, 1965.

[22] O. G. Sorokhtin and S. A. Ushakov, Earth Development, MGU Publishing House, Moscow, Russia, 2002.

[23] A. M. Dziewonski and D. L. Anderson, "Preliminary reference Earth model," Physics of the Earth and Planetary Interiors, vol. 25, no. 4, pp. 297-356, 1981.

[24] V. Yu and Burmin, "Distributions of density and elastic parameters in the Earth," Izvestiya Physics of the Solid Earth, vol. 42, no. 7, pp. 608-620, 2006.

[25] NASA. https://nssdc.gsfc.nasa.gov/planetary/planets/ mercurypage.html.

[26] C. Seligman, "The internal temperatures and magnetic fields of the planets," 2016, https://cseligman.com/text/planets/ magnetism.htm.

[27] A. Blokh, Y. A. Zhuravlev, and L. N. Ryzhkov, Heat Transfer by Radiation, Energoatomizdat, Moscow, Russia, 1991.

[28] V. I. Baikov, N. V. Pavlyukevich, A. K. Fedotov, and A. I. Shnip, Thermodynamics of Irreversible Processes. Theory of Convective Heat Transfer. Energy Transfer of Thermal Radiation. Transfer Processes and Phase Transformations in Solids, Institute of Heat and Mass Transfer Named after A. V. Lykov of the National Academy of Sciences of Belarus, Minsk, Belarus, 2014.

[29] I. S. Kulikov, D. V. Kadnikova, and V. S. Shvyidkiy, "Approximate methods for solving the radiation transfer 
equation," in Proceedings of the Heat Engineering and Informatics in Education, Science and Production: A Collection of Reports of the II All-Russian Scientific-Practical Conference of Students, Graduate Students and Young Scientists (TIM'2013) with International Participation, Yekaterinburg, Russia, March 2013.

[30] B. M. Yavorskiy and A. A. Detlaf, "Physics handbook," 1977, http://www.plib.ru/library/book/14222.html.

[31] G. B. Dwight, Integral Tables and Other Mathematical Formulas, Nauka, Moscow, Russia, 1973.

[32] Z. Konôpková, R. S. McWilliams, N. Gómez-Pérez, and A. F. Goncharov, "Direct measurement of thermal conductivity in solid iron at planetary core conditions," Nature, vol. 534, no. 7605, pp. 99-101, 2016.

[33] V. G. Gorshkov, A. M. Makarieva, and K. S. Losev, "Planetary greenhouse effect and the biotic stability of the Earth's climate," Transactions of the Earth Sciences Section of the Russian Academy of Natural Sciences, vol. 7, pp. 62-74, 2001.

[34] V. Morgalyuk, New Vision of the Problem of the Heat Flow of the Earth, INEOS, London, UK, 2016.

[35] M. I. Budyko and K. Y. Kondratyev, "Atmosphere of the Earth," Great Soviet Encyclopediapp. 380-384, Soviet Encyclopedia, Moscow, Russia, 3rd edition, 1970.

[36] D. R. Lide, Handbook of Chemistry and Physics, CRC, Boca Raton, FL, USA, 1996.

[37] V. M. Karpenko and O. V. Karpenko, "Energy information analysis of oscillations of a physical oscillator of inhomogeneous half-space," Geoinformatics, vol. 45, pp. P31-P48, 2013.

[38] V. N. Karpenko and A. I. Polituchiy, "Modeling of the process of multistage heating of electric machines," in Technical Electrodynamics, National Academy of Sciences of Ukraine, Kyiv, Ukraine, 2002.

[39] Y. Starodub, V. Karpenko, V. Karabyn, and V Shuryhin, "Mathematical modeling of the earth heat processes for the purposes of ecotechnology and civil safety," in Proceedings of the 2020 IEEE 15th International Scientific and Technical Conference on Computer Sciences and Information Technologies, CSIT 2020-Proceedings, pp. 146-149, Zbarazh, Ukraine, 2020. 